Isotopes in inverse modeling

\section{Isotope data improve the predictive capabilities of a marine biogeochemical model}

\section{T. Van Engeland ${ }^{1,2}$, A. De Kluijver ${ }^{1}$, K. Soetaert ${ }^{1}$, F. J. R. Meysman ${ }^{1,2}$, and} J. J. Middelburg ${ }^{1,3}$

${ }^{1}$ Department of Ecosystem Studies, Royal Netherlands Institute for Sea Research (NIOZ-Yerseke), Korringaweg 7, 4401NT Yerseke, The Netherlands ${ }^{1}$

${ }^{2}$ Faculty of Science, Vrije Universiteit Brussel, Pleinlaan 2, 1050 Elsene, Belgium

${ }^{3}$ Faculty of Geosciences, Utrecht University, P.O. Box 80021, 3508 TA Utrecht, The Netherlands

Received: 12 June 2012 - Accepted: 17 June 2012 - Published: 27 July 2012

Correspondence to: T. Van Engeland (tom.van.engeland@nioz.nl)

Published by Copernicus Publications on behalf of the European Geosciences Union.

\footnotetext{
${ }^{1}$ Formerly the Centre for Estuarine and Marine Ecology, NIOO-KNAW
}

T. Van Engeland et al.

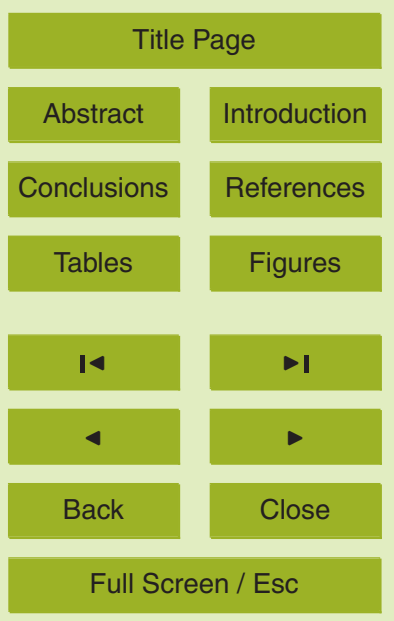

Printer-friendly Version

Interactive Discussion 


\section{Abstract}

Mesocosm experiments combined with biogeochemical modeling provide a powerful research tool to better understand marine ecosystem processes. Using an extended Nutrient-Phytoplankton-Zooplankton-Detritus (NPZD) model, we investigated

5 the added value of stable isotope tracer additions to constrain biogeochemical transformations within a mesocosm experiment that was designed to study ocean acidification effects on the marine ecosystem. Markov-Chain Monte-Carlo simulations revealed that even when isotope data were available for the majority of the components, not all parameters in the model could be constrained by calibration. However, when isotope tracer data were deliberately excluded from the calibration, the overparameterisation was even stronger. More specifically, it led to unconstrained fluxes through the zooplankton and detritus compartment, and different relative contributions of these two compartments to phytoplankton biomass loss produced equally plausible results. It is concluded that model uncertainty due to overparameterisation can be considerably 15 reduced by explicitly resolving stable isotope dynamics. Therefore, this mesocosm experiment has benefitted substantially from isotope tracer additions to unravel carbon cycling under varying $\mathrm{CO}_{2}$ regimes.

\section{Introduction}

Mesocosm experiments present an excellent research tool to study carbon perturbation effects on ocean processes because they allow for experimental manipulation and intensive sampling, and have an optimal balance between ecosystem complexity and realism (e.g. simplified transport setting, phytoplankton functional groups instead of monoculture). For the same reasons, mesocosm experiments are also used in conjunction with simple biogeochemical models (Vallino, 2000). The added value of the
BGD

9, 9453-9486, 2012

Isotopes in inverse modeling

T. Van Engeland et al.

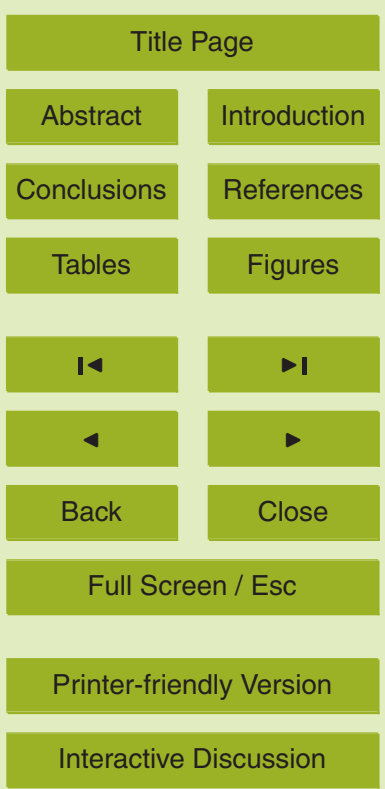

Interactive Discussion 
to measure (Jackson and Eldridge, 1992), and an improved understanding of the observed processes and patterns (Joassin et al., 2011).

Large mesocosm studies typically involve substantial multi-disciplinary effort, whereby many ecosystem variables and rates are measured. It is imperative that the 5 maximal amount of information is extracted from these data. An appropriate biogeochemical model can greatly facilitate this. In addition, models can facilitate verification and uncertainty assessment of the experimental findings, such as relationships between environmental stressors and ecosystem processes, which are often transferred to Earth System Models (ESMs, e.g. Gehlen et al., 2007; Ridgwell et al., 2007). Con10 sidering the increased application of ESMs as predictive tools to address global change issues, controlling uncertainty in this transferred knowledge is essential.

In the process of model calibration, the parameter values are modified until the model output matches the data from the mesocosm experiment. However, if not enough independent data are available to confidently estimate all parameters, the model is over15 parametrised relative to this calibration dataset. This typically results in an infinite number of parameter sets that allow the model to adequately fit the data (Matear, 1995). Despite the good fit to the measured data, these different parameter sets can cause the model to behave differently in variables for which no calibration data were available. This implies that the response of the model to environmental or experimental forcings such as changing $\mathrm{pCO}_{2}$ may differ, and that predictions beyond the calibration data can be biased. Therefore, this model overparameterisation can be an important contributor to uncertainty in model output (Stukel et al., 2012), which in turn reflects uncertainty in the experiment that was modelled.

In theory, overparameterisation can be countered in two ways: either by model simplification, or by extension of the calibration dataset (Van Oevelen et al., 2010). Frequently, model complexity is largely dictated by the question at hand, and both overly simple and overly complex models may perform poorly (Raick et al., 2006). If discarding information by model simplification is not desirable, additional calibration data are needed to constrain the model parameters.

\section{BGD}

9, 9453-9486, 2012

Isotopes in inverse modeling

T. Van Engeland et al.

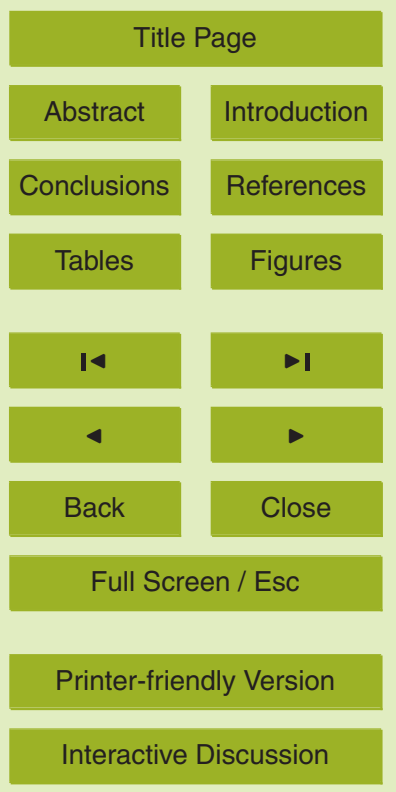

Interactive Discussion 
One such source of additional data is the stable isotope composition of the ecosystem compartments (Jørgensen, 1979). Explicit modeling of the heavy and light isotopes (e.g. ${ }^{13} \mathrm{C}$ and ${ }^{12} \mathrm{C}$ ) essentially doubles the amount of mass balance equations, while the biogeochemical transformations of the different isotopes are governed by the same 5 rate parameters. Clearly, when isotope fractionation is important, transformation rates need to be corrected by a fractionation factor. In this respect, it is important to distinguish between the use of stable isotopes at natural abundance and as deliberate tracers. In natural abundance studies isotope fractionation can cause relatively strong differences in the net isotope transfer rates between ecosystem compartments. When 10 isotope fractionation is well constrained (as is often the case - see for instance Post 2002), the fractionation factors can be included in models as fixed parameters. In the context of tracer additions, fractionation is often negligible due to the strong heavy isotope enrichment. In this case, the inclusion of isotope dynamics does not increase the number of model parameters, while the model can be fitted to additional isotopic 15 data. This effectively reduces the degree of overparameterisation, and the amount of uncertainty in the model output (Koopmans and Dam, 1998; Van Oevelen et al., 2006).

A number of deliberate tracer studies have already shown how isotope data can help to constrain models. Cole et al. (2002) succeeded in distinguishing allochtonous from autochtonous organic matter in a lake ecosystem, which enabled them to identify autochtonous food as the primary source to higher trophic levels in a fresh water lake. Van Oevelen et al. (2006) identified a herbivorous and detrital-microbial pathway as largely autonomous on a tidal mudflat, based on an integration of isotope data with a linear inverse model. These authors also demonstrated a progressive improvement of model predictions upon inclusion of standard biomass data, natural abundance isotope data, and isotope tracer data, respectively. The mesocosm context is not essential to isotope modeling, but delibrate tracer additions are particularly interesting in mesocosm experiments. Van den Meersche et al. (2004) could distinguish phytoplankton DOC exudates from recycled DOC, which enabled them to accurately quantify bacterial turnover rates and phytoplankton exudation in a mesocosm experiment. De Kluijver et al.
BGD

9, 9453-9486, 2012

Isotopes in inverse modeling

T. Van Engeland et al.

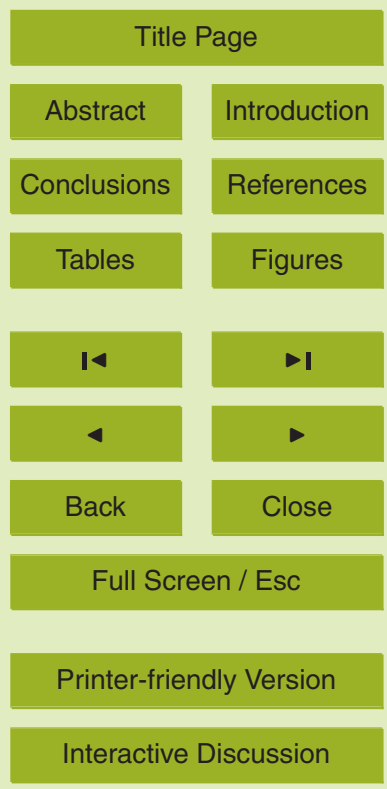


(2010) studied the effect of elevated $\mathrm{CO}_{2}$ on carbon transfer from phytoplankton to bacteria using ${ }^{13} \mathrm{C}$ as a deliberate tracer. Without isotope tracers these fluxes would have remained undistinguishable and unquantified.

In the framework of the "European Project on Ocean Acidification" (EPOCA), a meso5 cosm experiment was conducted in Ny Ålesund on Svalbard to investigate the effects of elevated $\mathrm{CO}_{2}$ on planktonic communities (Schulz et al., 2012). In a companion study De Kluijver et al. (2012) combined a dynamic non-linear ecosystem model with ${ }^{13} \mathrm{C}$ additions to quantify the carbon cycling under elevated $\mathrm{CO}_{2}$ levels in these enclosures. Here we focus on the parameter uncertainty in this pelagic biogeochemical model. More specifically, we analyse how ${ }^{13} \mathrm{C}$ isotope data can help reduce the overparameterisation of the biogeochemical model, and hence reduce the uncertainty on rates and fluxes predicted by the model. Clearly, there is a trade-off between reduced parameter uncertainty and increased measurement effort. Accordingly, the question is how strongly additional isotope measurements can improve our estimates of carbon 15 transfers between ecosystem compartments in a pelagic biogeochemical model.

\section{Material and methods}

\subsection{Experimental dataset}

In summer 2010, a pelagic mesocosm experiment was conducted in Ny Ålesund, Svalbard $\left(78^{\circ} 56.2^{\prime} \mathrm{N}, 11^{\circ} 53.6^{\prime} \mathrm{E}\right)$ in the framework of the EPOCA project. For a full description of the experimental setup, we refer to Czerny et al. (2012) and Schulz et al. (2012). Briefly, the experiment consisted of 9 floating mesocosm enclosures of $\sim 50 \mathrm{~m}^{3}$ that were kept at different $p \mathrm{CO}_{2}$ levels, representing future atmospheric $\mathrm{CO}_{2}$ concentrations (Bellerby et al., 2012). The experiment, which lasted for 30 days, was conducted in two phases. Over the first 12 days, pelagic communities developed at ambient nutri-
BGD

9, 9453-9486, 2012

Isotopes in inverse modeling

T. Van Engeland et al.

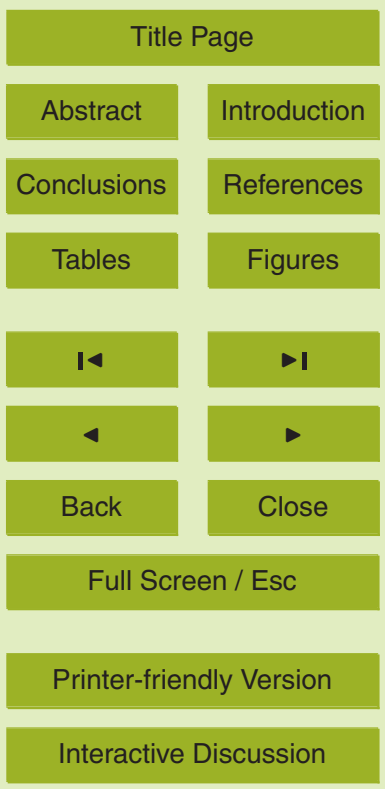

Interactive Discussion 
to induce a plankton bloom. At the start of the experiment, labelled dissolved inorganic carbon $\left(\mathrm{DI}^{13} \mathrm{C}\right)$ was added at enrichment level of $100 \%$.

Most ecosystem variables were sampled on a daily basis, except for data from the sediment traps, which were sampled every 2nd day (Czerny et al., 2012), and zoo5 plankton samples, which were taken on a weekly basis. $\delta^{13} \mathrm{C}$ was determined in total particulate organic carbon (POC), zooplankton, dissolved inorganic carbon (DIC), sedimented detritus, and polar lipid-derived fatty acids (PLFA) to resolve the microbial domain (De Kluijver et al., 2012). The variables used for calibration are given in Table 1.

Our analysis focuses on the role of isotope data in model calibration and parameter 10 uncertainty. As parameter values can change under different acidification and nutrient regimes, we selected the data obtainted during the unperturbed operation of the mesocosm ecosystems (i.e. two control enclosures with present day $\mathrm{CO}_{2}$ conditions and data obtained during the first phase without nutrient addition). The application of the same model to all 9 enclosures (i.e. under different $\mathrm{CO}_{2}$ regimes) is detailed in 15

\subsection{Model description}

The biogeochemical model is an extended NPZD model (nitrogen-phytoplanktonzooplankton-detritus) that additionally includes dissolved organic carbon (DOC), dissolved organic nitrogen (DON), heterotrophic bacteria, and sedimentary detritus. It has

2014 state variables (Tables 1 and 2), incorporates 23 parameters (Table 3), and uses carbon as currency with separate pools for the light and heavy isotopes in most compartments. Fixed C: $\mathrm{N}$ ratios (Redfield) are implemented to link the carbon and nitrogen cycle.

Two functional types of phytoplankton are distinguished based on experimental ob25 servations. Polar lipid-derived fatty acids (PLFA) showed that the first group (Phyto $)$ consisted mainly of autotrophs (green algae, prymnesiophytes, and autotrophic dinoflagellates), the second group (Phyto ${ }_{\|}$) contained both autotrophs (diatoms) and heterotrophs (dinoflagellates; De Kluijver et al., 2012).
BGD

9, 9453-9486, 2012

Isotopes in inverse modeling

T. Van Engeland et al.

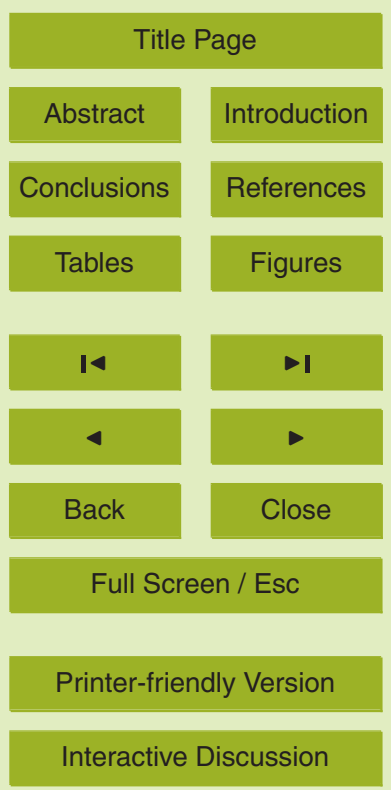


Because the data showed no strong changes in bacterial and zooplankton biomasses (De Kluijver et al., 2012; Niehoff et al., 2012), they are assumed constant in the model, and only their isotopic composition is allowed to change. As a result, only their ${ }^{13} \mathrm{C}$ content is modelled as a state variable, and their total biomasses are 5 implemented as parameters (Tables 1, 2, and 3).

The measured irradiance $(I)$ and the measured concentrations of $\mathrm{DI}^{13} \mathrm{C}$ and $\mathrm{DI}^{12} \mathrm{C}$ are imposed as forcings upon the model. The latter simplification allowed us to focus on carbon transfer within the foodweb without explicitly accounting for air-sea $\mathrm{CO}_{2}$ exchange (affected by the bubbling of the mesocosm enclosures). A number of events 10 related to experimental manipulations and observations are forced upon the model as well. The concentration of particles caught in sediment traps was reset to zero every 2nd day, coincident with sediment trap sampling. In addition, phytoplankton mortality was only switched on from day 6 , since the nature of the increase in phytoplankton isotope signature combined with the increase in phytoplankton carbon indicated that 15 mortality had to be negligible in the first few days. Moreover, high viral abundances were observed in the mesocosms from day 6 onwards, coincident with a bloom collapse (Brussaard et al., 2012). This implies that the phytoplankton mortality rate was strongly time dependent. In between sediment collection, nitrogen is conserved in the model (DIN + PON $+\sum_{\text {time }} \mathrm{N}_{\text {Sed }}=$ constant), but not carbon because DIC is implemented 20 as a forcing (Table 2).

Apart from the bacteria and zooplankton (see above), for which only ${ }^{13} \mathrm{C}$ is modelled, all biotic compartments are split up in a heavy and a light isotope sub-compartment (cf. Table 1). Fluxes are calculated based on the total concentrations of the compartments (see below and Fig. 1), and the subdivision between ${ }^{13} \mathrm{C}$ and ${ }^{12} \mathrm{C}$ is only made in the mass balance equations (Table 2) by assuming that, except for carbon fixation, no isotopic fractionation occurs in any of the fluxes. This is accomplished by multiplying the total mass fluxes by the isotope fractions $\left(F_{j}^{13} \mathrm{C}={ }^{13} \mathrm{C}_{j} /\left({ }^{13} \mathrm{C}_{j}+{ }^{12} \mathrm{C}_{j}\right)\right.$ and $\left.F_{j}^{12} \mathrm{C}=1-F_{j}^{13} \mathrm{C}\right)$ of the relevant source compartment (j). Isotope fractionation during carbon fixation is
BGD

9, 9453-9486, 2012

Isotopes in inverse modeling

T. Van Engeland et al.

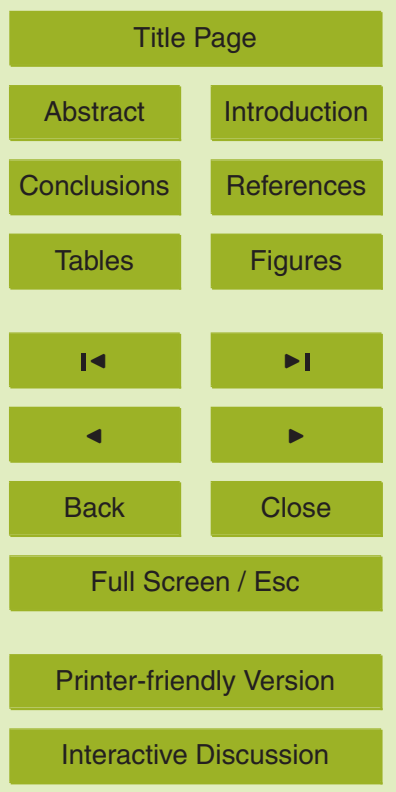


accomplished by multiplying the actual ${ }^{13} \mathrm{C}$ isotope fraction of DIC by a preference factor (pref) smaller than 1, giving some priority to ${ }^{12} \mathrm{C}$ in the mass balance equations of the phytoplankton-related state variables (Eq. 4). This preference factor is set to 0.956 , based on the observed difference between $\delta^{13} \mathrm{C}_{\mathrm{DIC}}$ and $\delta^{13} \mathrm{C}_{\mathrm{Phyto}}$ upon saturation of 5 the latter compartment.

Phytoplankton growth (for individual phytoplankton groups: $i \in\{I, I I\}$ ) depends on irradiance $(I)$ and DIN availability through Monod-kinetics (Eq. 5). The phytoplankton groups have their own maximal growth rate $\left(\mu_{i}\right)$, but share the same half-saturation constants $\left(k s_{N}\right.$ and $\left.k s_{l}\right)$. Phytoplankton mortality is first-order dependent on phytoplankton biomass (Eq. 6), and is split up over an input into the DOM pool (Eq. 7), an input into the detritus pool (Eq. 8), and a respiratory component (Eq. 9). Phytoplankton DOM exudation depends linearly on phytoplankton growth (Eq. 10).

Zooplankton grazing on the phytoplankton is modelled through Monod-type dependence on the biomass of the two phytoplankton compartments ( $\mathrm{i} \in\{\mathrm{I}, \mathrm{II}\}$; Type II functional response; Eq. 11). Because their biomass is assumed constant, the biomass gain from zooplankton grazing is immediately lost. This loss is subdivided over a respiratory component (Eq. 12), suspended detritus (Eq. 13; faeces production), and sedimented detritus (Eq. 14; because the zooplankton actively migrated into the sediment traps; Niehoff et al. 2012; De Kluijver et al. 2012).

20 Bacterial growth is modelled through a Monod dependence on the labile DOC concentration (Eq. 15). Just as for the zooplankton, bacterial biomass is kept constant in the model, hence any gain term is immediately balanced by a loss. Therefore, bacterial respiration is set equal to bacterial growth (Eq. 16).

DOM originating from phytoplankton loss and exudation is labile in nature and adds tory DOC is implemented as a parameter (Tables 2 and 3). Both DON and labile DOC are consumed in bacterial growth (Table 2). Dissolved organic matter and detritus mineralisation are first-order dependent on the respective pool sizes, using the same rate

BGD

9, 9453-9486, 2012

Isotopes in inverse modeling

T. Van Engeland et al.

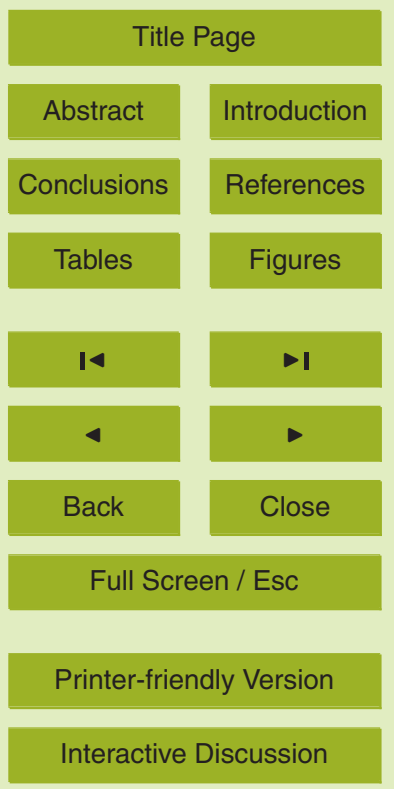

Interactive Discussion 
constant (Eqs. 17 and 18). Suspended particles are lost from the detritus pool through sinking, and are deposited into the sediment trap (Eq. 19).

The model was implemented in Fortran and embedded within an add-on package ("EPOCA") for the R statistical software (R Development Core Team, 2011). This pack5 age is provided with the paper as supplement. Integration of the ordinary differential equations (Table 2) was performed using the R-package "deSolve" (Soetaert et al., 2010).

\subsection{Model analysis}

The FME package (Flexible Modelling Environment, version 1.2; Soetaert and Petzoldt, 2010) for the R Statistical Software (version 2.14; R Development Core Team, 2011) was used to perform sensitivity and uncertainty analyses, and model calibrations. To assess the added value of isotope data to constrain the model, it was calibrated to two observational datasets. A first dataset contained $\delta^{13} \mathrm{C}$ values as well as concentrations/biomasses of the ecosystem compartments (Table 1). This will be referred to as the full dataset, and is here considered the reference. A second calibration dataset consisted of the subset with only concentrations/biomasses. This will be referred to as the reduced dataset.

\subsubsection{Model sensitivity}

Model sensitivity to a parameter is the amount of change in the model output that is caused by a change in the parameter value. Formally, the sensitivity of a modelled variable $V$ to a parameter $p$ at a specific time point $t$, when observation $i$ was taken, is defined as the scaled partial differential (Brun et al., 2001)

$S_{V}\left(t_{i}\right)=\frac{\partial V\left(t_{i}\right)}{\partial p} \times \frac{p}{V\left(t_{i}\right)}$.
BGD

9, 9453-9486, 2012

Isotopes in inverse modeling

T. Van Engeland et al.

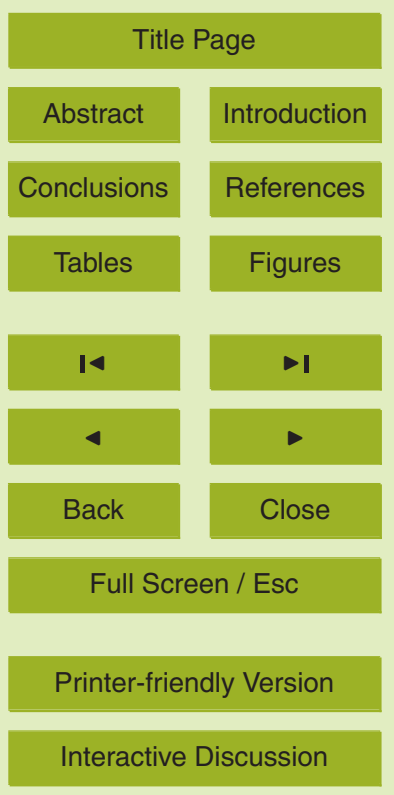


The scaling renders the model sensitivity independent of the physical units and magnitude of the parameter and variable. The overall result of such a sensitivity analysis is a sensitivity matrix, in which each column represents the temporal evolution of all the variable sensitivities to a specific parameter. For a dynamic model with $N$ variables, $5 i$ output points coincident with $i$ observations in the calibration data, and $p$ parameters, this is a $(N \cdot i) \times p$ matrix, $\mathbf{S}$. The information in this matrix can be summarized by calculating several quantities such as the mean and L2-norm (Brun et al., 2001).

Sensitivity analysis serves two purposes: (1) assessment of uncertainty in the modelled variables with regard to variation or uncertainty in a parameter, and (2) identifica10 tion of suitable candidate parameters for model calibration: only when a model is sensitive to a parameter, we can change the parameter to make the model better approach the data (minimize the cost function). Here we will focus on the second application.

Good candidate parameters for optimization should not only exert sufficient model sensitivity, but also be independent of one another. Existence of a significant relation15 shi ship between the sensitivities of a variable with respect to two parameters implies that a change in one parameter can be compensated by a proportional change in the other parameter. This is investigated by an identifiability analysis. This analysis, which is based on the sensitivity matrix, investigates correlations (between two parameters) and multicollinearity (between more than two parameters). For the latter a multicollinearity index was used (Brun et al., 2001), which is defined as:

$M I=\lambda_{\min }^{-1}$

with $\lambda_{\text {min }}$ the smallest singular value of the rescaled sensitivity matrix $\mathbf{S}_{s}$. This rescaling occurs through dividing the columns of $\mathbf{S}\left(\boldsymbol{S}_{., p}\right)$ by their respective norms:

$S_{S_{., p}}=\frac{S_{., p}}{\left\|S_{., p}\right\|}$,

25 where $p$ refers to the fact that a column is parameter-specific. A large multicollinearity index implies strong dependence among parameter sensitivities, and therefore strong 9462

\section{BGD}

9, 9453-9486, 2012

Isotopes in inverse modeling

T. Van Engeland et al.

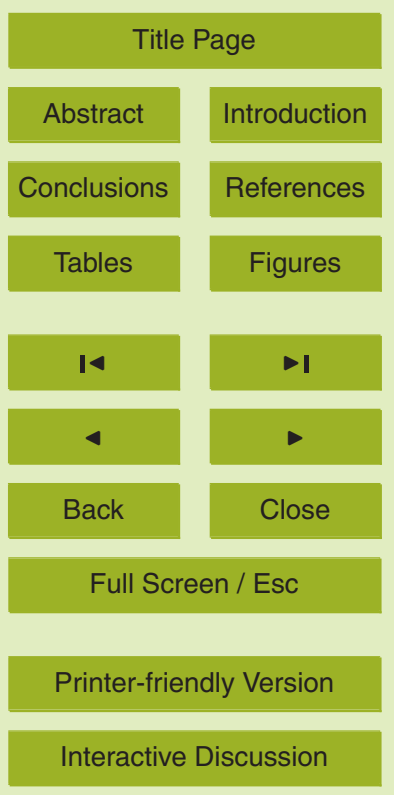


overparametrization and poor identifiability of the inverse problem of parameter optimization.

Parameters that eventually can enter the calibration procedure are called tunable parameters. Those that cannot be estimated in a calibration are fixed at a value, based 5 on expert judgement.

\subsubsection{Model calibration}

In a first phase the model was calibrated to a mesocosm dataset which contained concentration and isotope data (i.e. full dataset). This calibration was done in three steps: (1) manual calibration with consideration of all parameters, (2) automatic calibration of a subset of rate parameters that exhibited sufficient model sensitivity, and (3) refinement and verification of this first automatic calibration using a Markov-Chain Monte-Carlo (MCMC)-based search algorithm. In a second phase, calibration based on only the concentration data was performed, and involved essentially a repetition of step 2 and 3, starting from the parameter values that resulted from the first phase. The different steps are explained in more detail below.

A manual calibration of individual parameters: This calibration was intended to bring the model cost function in the vicinity of its minimum (based on the full dataset; first phase, step 1). The model cost was here defined as the weighted least squares error, in which the residuals per variable are rescaled by dividing them by the variable mean. This is necessary to obtain costs independent of the units and of the variable's magnitude. For each parameter a limited number of model outputs were generated for parameter values in a plausible range. Subsequently, the parameter was set at the value that corresponded to a minimal cost. The order in which the parameters were set was dictated by the model's sensitivity, as indicated by the $\mathrm{L} 2$ column norms of the sensitivity matrix, $\mathbf{S}$.

Parameter selection for step 2 in the first phase: Because simultaneous optimisation of 23 parameters based on the available data was not possible, we decided to focus on parameters that represented transformation rates. Therefore, a set of candidate
BGD

9, 9453-9486, 2012

Isotopes in inverse modeling

T. Van Engeland et al.

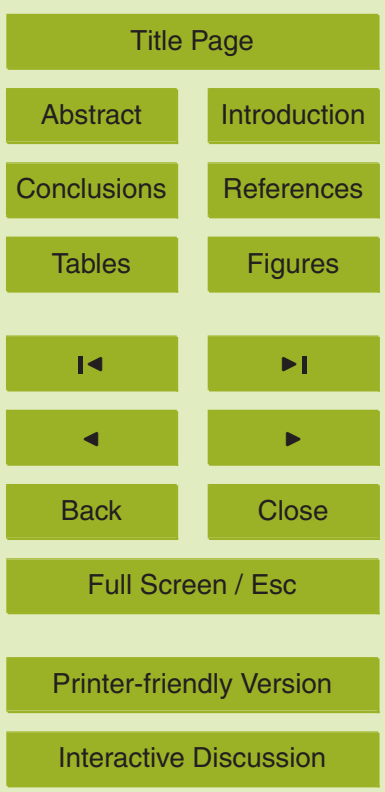

Interactive Discussion 
parameters was selected after the initial manual calibration, such that each parameter represented exactly one transformation in the model (i.e. eligible). We decided to keep the half-saturation constants fixed and the maximal growth/grazing rates eligible for tuning. Subsequently, this reduced set of eligible parameters was subjected to sen5 sitivity and identifiability analyses to guide a further selection of parameters that could be included in the final automatic calibration (see Sect. 2.3.1). The subset of parameters that exhibited high model sensitivity and low mutual dependence (i.e. tunable parameters) were considered for automatic calibration (first phase, step 2; Table 3).

The first automatic calibration: This first calibration (first phase, step 2), starting from 10 a reasonable parameter set that was provided by the manual calibration, was performed using the Levenberg-Marquardt fitting algorithm (LMA) (Moré, 1978). In the FME package LMA returns a parameter covariance matrix, based on the Jacobian. This was considered a first guess of the multivariate parameter distribution (Soetaert and Petzoldt, 2010), which was used as initial input for the MCMC-based calibration 15 (step 3).

Second calibration using Markov-Chain Monte-Carlo (MCMC) simulations (first phase, step 3): These simulations used an adaptive Metropolis algorithm including a delayed rejection procedure (DRAM; Haario et al. 2006), in which new parameter values were suggested based on a multivariate normal distribution. This distribution was initially defined by the parameter covariance matrix of the Levenberg-Marquardt routine (step 2), and updated with parameter covariance information from the MCMC simulation at regular intervals throughout the simulation to speed up convergence. The procedure is explained by Soetaert and Petzoldt (2010). This resulted in robust nonparametric joint distributions for the parameters (Gelman et al., 2004).

Parameters with unacceptable high correlations were discarded, and the procedures of step 2 and 3 repeated until the final MCMC calibration only contained parameter randomisations that exhibited sufficiently low dependence between parameters (see Sect. 3.1). Parameter dependence could still be encountered after the initial identifiability analysis, because identifiability analysis only provides information for the parameter
BGD

9, 9453-9486, 2012

Isotopes in inverse modeling

T. Van Engeland et al.

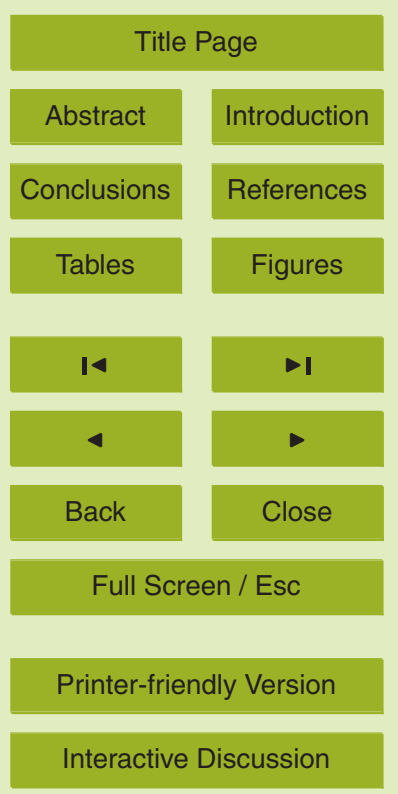


values used in the analysis (i.e. local in parameter space), while model calibration yields a new parameter set. Hence, the iterative nature of model calibration.

For the second phase (calibration based on the subset of concentration data only, i.e. reduced calibration dataset), steps 2 and 3 were repeated once, starting from the 5 final parameter set of the first phase. Since the presence of isotope data was the only difference between both calibrations, the differences in the resulting parameter values and their uncertainty were only due to the absence of isotope data in the reduced calibration dataset.

\section{Results and discussion}

\subsection{A maximally constrained model}

In the first phase with model calibration based on the full dataset (isotopes and concentrations), 11 out of 23 parameters were considered tunable after sensitivity and identifiability analyses (Table 3). The remainder of the parameters were fixed at values determined during manual calibration (step 1, cf. Sect. 2.3.2). The multicollinearity 15 rameters $(=4.5)$, indicating much stronger mutual dependence in the larger parameter set. index for the 23 parameters $(=11.4$ ) was much higher than that for the subset of 11 pa-

Subsequent, automatic calibrations (steps 2 and 3, cf. Sect. 2.3.2) pointed out that still multiple correlations existed between these 11 parameters. Four parameters $\left(\gamma_{l}, \gamma_{l l}, \rho\right.$, and $\left.\xi_{\text {Zoo }}\right)$ involved in these correlations were fixed one at a time at their value after the initial manual calibration (step 1), and automatic calibrations were repeated (steps 2 and 3). Eventually only 7 parameters could be independently estimated in the final MCMC calibration (cf. Table 4, and values in bold in Table 3). Overall, the model was quite successful in reproducing the calibration data (Fig. 2), but even this simple

\section{BGD}

9, 9453-9486, 2012

Isotopes in inverse modeling

T. Van Engeland et al.

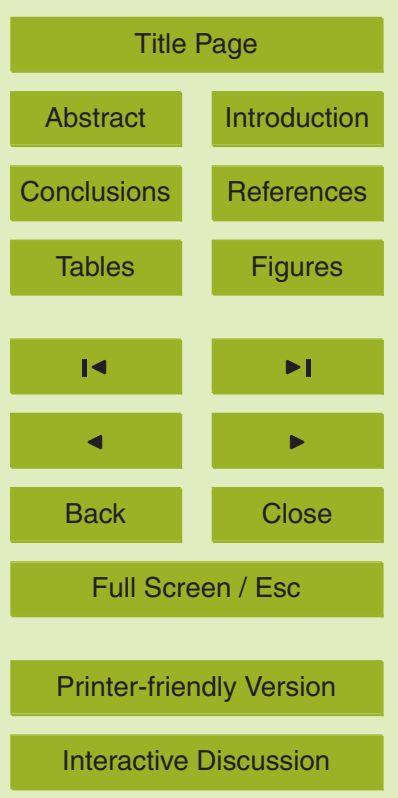


The parameter randomisations from the final MCMC calibration based on the full dataset (i.e. reference calibration) showed no drift (data not shown), indicating that the parameter estimates had converged to stable values. Figure 3 gives the parameter covariance matrix, which essentially represents the joint distributions of the optimized 5 parameters. Only a relatively week correlation remained between the growth $\left(\mu_{l}\right)$ and mortality $\left(\xi_{l}\right)$ parameter of Phyto (Fig. 3). Therefore, parameter values were considered independent of one another. As a result, their standard errors were representative of the uncertainty in the estimates, provided that the fixed parameter values can be considered known (Table 4). Tunable parameters always have distributions conditional 10 on the fixed parameter values (Brun et al., 2001). Hence, a priori fixed parameters are essentially model assumptions. They require further investigation and proper documentation if they are involved in strong correlations with ecologically relevant parameters or parameters that are transferred to other models (see for instance Rose et al., 2007; Zobitz et al., 2011).

\subsection{Model without isotope data}

In the second phase (involving only automatic calibrations, cf. Sect. 2.3.2), the 7 fitted parameters from the first phase were estimated again based on concentration data only (reduced dataset). Since this calibration procedure started from the same initial conditions and fixed parameter values, and used the fitted parameter values of the reference calibration as starting values, the differences in the resulting parameter estimates were solely attributable to differences in the calibration datasets, i.e. presence/absence of isotope data.

All parameter standard deviations (sd) were higher in this calibration than in the reference calibration based on the full dataset, illustrating that the parameter set from parameters exhibited stronger correlations than in the reference calibration (compare Fig. 4 with Fig. 3). The detritus sinking rate $\left(r_{\text {sink }}\right)$ correlated negatively $(r=-0.78)$ with the maximal zooplankton grazing rate $\left(\mu_{g}\right)$, indicating that alternative pathways

\section{BGD}

9, 9453-9486, 2012

Isotopes in inverse modeling

T. Van Engeland et al.

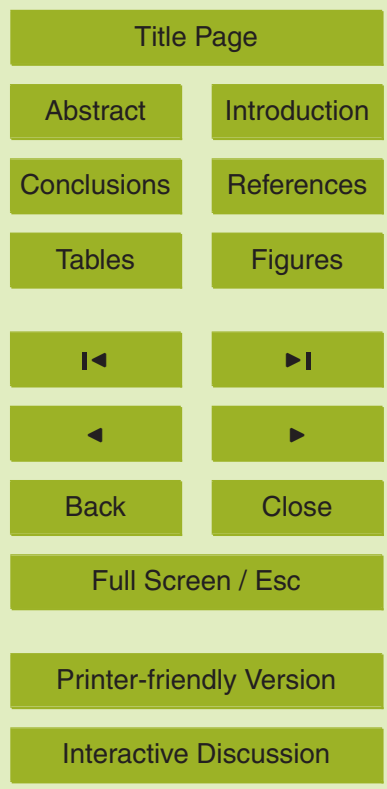

Interactive Discussion 
out of the phytoplankton were not well constrained. As a result, without the isotope data it would have been impossible to draw conclusions about particle export unless assumptions about zooplankton grazing rates were made. Relative to the reference calibration, the maximal zooplankton grazing rate $\left(\mu_{\mathrm{g}}\right)$ was overestimated while the 5 specific detritus sinking rate $\left(r_{\text {sink }}\right)$ was underestimated (Table 4$)$.

Estimates of phytoplankton maximal growth rates $\left(\mu_{i}\right)$ correlated positively with the respective mortality $\left(\xi_{i}\right)$ rates $(r=0.66$ and $r=0.72$ for group I and II, respectively; Fig. 4) due to high variability in the phytoplankton biomass data and the lack of isotopic information to constrain the carbon fixation rates. The estimate of the maximal bacterial 10 growth rate $\left(\mu_{\mathrm{Bac}}\right)$ was positively related to the growth and mortality of Phyto $_{\|}$but not of Phyto. . The reason was that exudation by Phyto $_{\|}$, which was coupled to carbon fixation, was the primary factor in DOC limitation of bacterial growth. Lower values for exudation had to be compensated in the parameter calibration by lower maximal bacterial growth rates because the half-saturation constant of DOC uptake was fixed. The stronger overparameterisation with respect to the reduced dataset was also reflected in a higher multicollinearity index (3.43 and 1.64 for the reduced and full dataset, respectively; data not shown).

These parameter correlations imply that changing one parameter could be compensated by proportional changes in correlating parameters, and therefore a nonuniqueness of the optimal parameter set. Consequently, it cannot be deduced from the model what happened in the mesocosm with respect to the corresponding ecosystem processes (see below). In addition, assuming that parameter transfer to another model is justified, it can be difficult to transfer a parameter that strongly depends on other parameters, unless the correlating parameters are transferred as well or they are

\subsection{Propagation of parameter uncertainty into model output}

Figures 3 and 4 represent two joint parameter distributions estimated by the MCMC calibrations based on the full and reduced dataset, respectively. By running the model

\section{BGD}

9, 9453-9486, 2012

Isotopes in inverse modeling

T. Van Engeland et al.

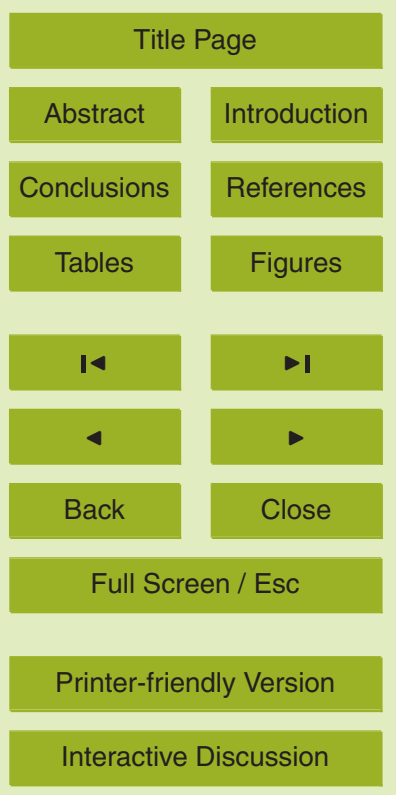


with 100 random samples from these distributions, the model output is estimated. Both the well constrained (Fig. 5a-h) and poorly constrained (Fig. 5i-p) parameter sets provided good fits.

Perhaps a bit counter-intuitive, the phytoplankton $\delta^{13} \mathrm{C}$ signatures were still correctly 5 estimated and only showed relatively small uncertainty, even in the scenarios that did not use isotope data for calibration (Fig. $5 \mathrm{k}$ and I). This is because phytoplankton maximal growth rates were the only parameters affecting the biomasses from day 0 to 6 . Based on the isotope data and information about viral densities, it was concluded before initiating the modelling that mortality during this period must have been negligible.

10 Therefore it was set to zero during this first period (Sect. 2.2). Inclusion of this prior knowledge based on isotope data allowed for a proper estimation of the phytoplankton maximal growth rate, even without isotope data.

Some of the modelled ecosystem variables that were not used in the calibration, such as $\delta^{13} \mathrm{C}_{\text {Zoo }}$, exhibited considerably higher uncertainty in the poorly constrained model 15 output (Fig. $5 \mathrm{~m}$ ). In addition, the simulated $\delta^{13} \mathrm{C}_{\text {Zoo }}$, based on the poorly constrained parameter set, was considerably lower than its counterpart in the well constrained model run and in the data. This is in line with the common finding that zooplankton is one of the least constrained components in aquatic biogeochemical models (Arhonditsis and Brett, 2004). This underestimation together with the severe overestimation of the detritus sinking rate (Fig. 5p) are a reflection of the under- and overestimation of the corresponding rate parameters (Table 4). Inclusion of isotope tracer additions in the experimental and model design enabled a better assessment of the carbon export rates, which is of major importance in ocean acidification modeling, considering the influence of ocean acidification on carbon export (Riebesell et al., 2007; De Kluijver

\subsection{Model sensitivity to isotope data}

The added value of isotope data is not equally important through time. Figure 6 shows the sensitivities (solid coloured lines and blocks) of $\delta^{13} \mathrm{C}$ values of the two 9468
BGD

9, 9453-9486, 2012

Isotopes in inverse modeling

T. Van Engeland et al.

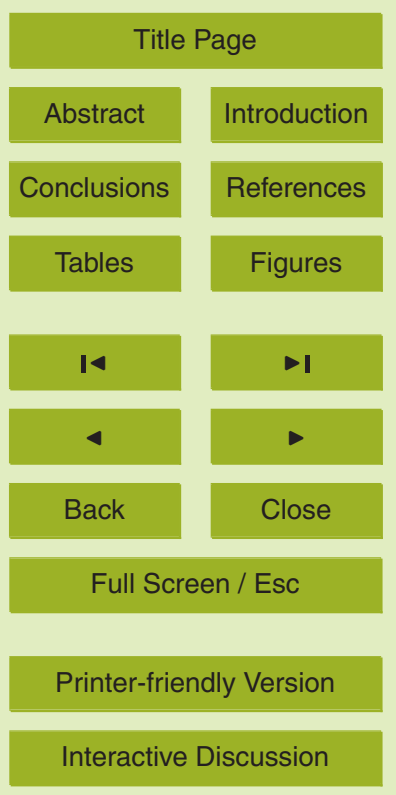

Interactive Discussion 
phytoplankton groups to their respective maximal growth rates. High sensitivities coincide with strong changes in variables, because the growth rates determine the carbon influx into the phytoplankton compartments. This influx has the isotope signature of its source (i.e. the DIC substrate). As the isotope composition of the respective ecosys5 tem compartments approaches that of their food source or substrate, the changes in composition decrease and sensitivities drop. Comparison between Phyto, (Fig. 6a) and Phyto $_{\|}$(Fig. 6b) shows that sensitivities remain high as long as the isotope composition of the respective compartments is altered. Because the turn-over of Phyto, is higher, its isotope composition approaches that of the DIC faster, and sensitivity decreases ear10 lier than in $\mathrm{Phyto}_{\|}$. This effect is inherent to isotope tracer experiments, and illustrates the need for tracer additions in several pulses under prolonged experimental conditions to avoid saturation (Carpenter et al., 2005).

As indicated at the beginning of Sect. 3.1, the model was overparameterised relative to the full calibration dataset $\left(\gamma_{l}, \gamma_{l l}, \rho\right.$, and $\xi_{Z o o}$ could not be estimated independently). 15 This is due to the lack of useful isotope data for the DOC pool. In the experiment, DOC exudation rates were not high enough relative to the large DOC background concentration, which resulted in very low enrichment of this pool, and hence large relative measurement errors in $\delta^{13} \mathrm{C}_{\mathrm{DOC}}$ (De Kluijver et al., 2012). If these data would have been available for calibration, they might have put constraints on the DOC exudation and remineralisation rates (Van den Meersche et al., 2011). Measuring exudation rates ex situ using more sensitive ${ }^{14} \mathrm{C}$ methods (see for instance Larsson and Hagström, 1982; Morán and Estrada, 2002) or using larger ${ }^{13} \mathrm{C}$ additions (Van den Meersche et al., 2011) could solve this problem. The lack of DOC data implies that conclusions or assertions concerning DOC production and consumption based on these experiments 25 should be made cautiously.

In the present model, isotope fractionation is only accounted for in carbon fixation. The fractionation was a priori estimated from the final difference in $\delta{ }^{13} \mathrm{C}$ between the phytoplankton and DIC (upon saturation of the isotope signature of $\mathrm{Phyto}_{\mathrm{I}}$ ). Carbon isotope fractionation in successive trophic levels is known to be small (Post, 2002), and
BGD

9, 9453-9486, 2012

Isotopes in inverse modeling

T. Van Engeland et al.

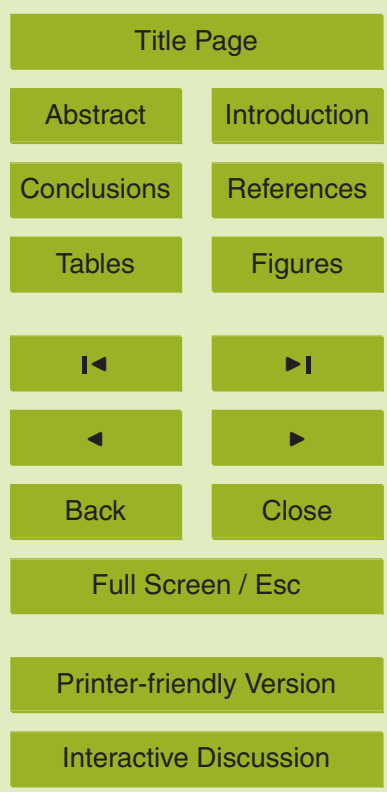


certainly negligible, compared to the isotope enrichment from the tracer pulse. However, the assumption of zero fractionation may not always be valid. In these cases, fractionation factors have to be either estimated or taken from literature (implying another assumption, that at least requires a sensitivity analysis to assess its propagation 5 into model uncertainty). As such, the advantage of isotope tracer measurements for model calibration will not always be as pronounced.

\section{Conclusions}

This study has illustrated that modeling mesocosm experiments enhances extraction of information from the experiments, and helps to identify and quantify uncertainties in the 10 experimental and sampling design. While all sampling, measurement and experimental efforts make specific assumptions about how to interpret observed patterns, models make these assumptions more explicitly in mathematical equations. Uncertainty analyses of this mathematical system can point out uncertainties in the experiment attributable to these assumptions. Therefore, experimental data is not only exploited by 15 modellers, but modeling can be directly beneficial to experimentalists as a quality control as well. In addition, uncertainty analyses help to define the condition under which such experimental findings and parameter values can be transferred to Earth System Models.

Most often, environmental models are used to estimate matter and energy trans20 fers between ecosystem compartments (Jackson and Eldridge, 1992). Stable isotope tracer data help to reduce overparameterisation by putting direct constraints on these transfers. Isotope tracer additions provide a cost-effective way of extending calibration datasets originating from mesocosm experiments, because they do not require additional incubation, measurement techniques and expertise are well developed, and most sampling techniques for isotope analyses are fairly standard. Because of the

\section{BGD}

9, 9453-9486, 2012

Isotopes in inverse modeling

T. Van Engeland et al.

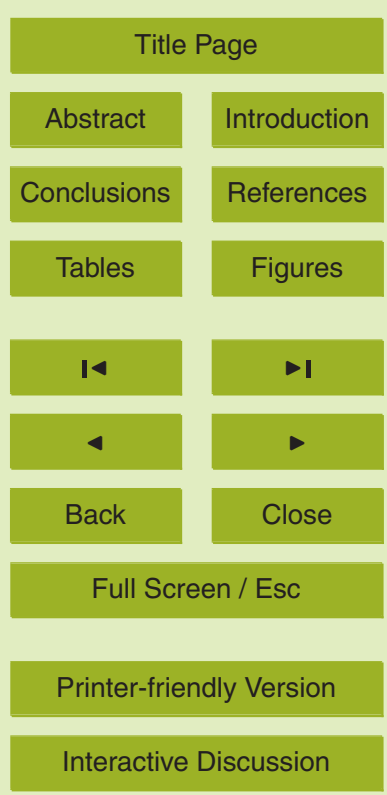


isolate a $\mathrm{CO}_{2}$-effect on carbon export and zooplankton grazing upon phytoplankton using a dedicated ecosystem model.

The problem of overparameterisation is ubiquitous in ecosystem modeling, and complicates model-based quantitative deduction. Our analyses revealed effects of overpa-

5 rameterisation on predictions of parameters and model output, ranging from simple decreases in the precision to larger changes in the relative contributions of specific fluxes. Since overparameterisation becomes more problematic as more ecosystem compartments and state variables are added, increasing model complexity only makes sense when dataset completeness follows (Arhonditsis and Brett, 2004). Considering that 10 parameter determination is one of the most challenging tasks in biogeochemical modeling (Ward et al., 2010), a rigorous assessment of the data requirements to constrain a model should be a standard part of model development.

Finally, the development of Markov-Chain Monte-Carlo techniques has opened new doors for exploring ecosystem models. Whereas least squares minimisation tends to select one mathematically parsimonious but not necessarily well-founded solution, Monte-Carlo simulations provide more sound information with regard to the robustness of a solution and select an average parameter set from a plausible parameter subspace that contains equally valid model solutions, given the data.

\section{Supplementary material related to this article is available online at: http://www.biogeosciences-discuss.net/9/9453/2012/ bgd-9-9453-2012-supplement.zip.}

Acknowledgements. This work is a contribution to the "European Project on Ocean Acidification" (EPOCA) which received funding from the European Community's Seventh Framework Programme (FP7/2007-2013) under grant agreement no. 211384. We gratefully acknowledge 25 the logistical support of Greenpeace International for its assistance with the transport of the mesocosm facility between Kiel and Ny Ålesund, the captains and crews of M/V ESPERANZA of Greenpeace and R/V Viking Explorer of the University Centre in Svalbard (UNIS) for their

Isotopes in inverse modeling

T. Van Engeland et al.

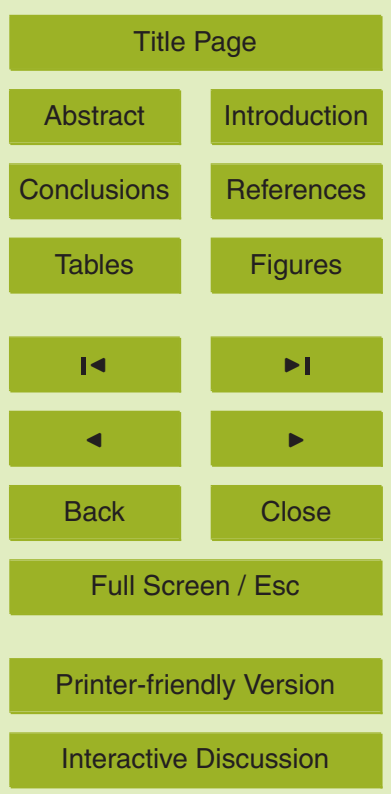


assistance during mesocosm transport, deployment and recovery in Kongsfjorden. We also thank the staff of the French-German Arctic Research Base at Ny Ålesund, in particular Marcus Schumacher, for on-site logistical support, and the staff of the Dutch Station, especially Maarten van Loon, for accommodation in Ny Ålesund. We also thank the mesocosm team for 5 support during fieldwork, and Pieter van Rijswijk and the NIOZ analytical lab for stable isotope analyses and lab support. We thank Richard Bellerby of Bjerkness Centre for Climate Research for DIC numbers and Tim Boxhammer, Jan Czerny, Kai Schulz, Ulf Riebesell and Anja Engel from Geomar for providing dissolved and particulate organic carbon nitrogen data, inorganic nutrients, light data and sediment trap samples and data. Mehdi Ghourabi is acknowledged for 10 his help with model construction. Finally, we are also grateful to Jan Czerny, and Kai Schulz for the fruitful discussions and their contribution to the analyses of the mesocosm data used for this study. Financial support was provided through Transnational Access funds by EU project MESOAQUA under grant agreement no. 22822, the European Project on Ocean Acidification (EPOCA, FP7, 2211384), and the Darwin Center for Biogeosciences supported by the Netherlands Organization for Scientific Research.

\section{References}

Arhonditsis, G. B. and Brett, M. T.: Evaluation of the current state of mechanistic aquatic biogeochemical modeling, Mar. Ecol.-Prog. Ser., 271, 13-26, 2004. 9468, 9471

Bellerby, R. G. J., Silyakova, A., Nondal, G., Slagstad, D., Czerny, J., De Lange, T., and Ludvig, A.: Description of the evolution of the carbonate system, Biogeosciences Discuss., in preparation, 2012. 9457

Brun, R., Reichert, P., and Kunsch, H. R.: Practical identifiability analysis of large environmental simulation models, Water Resour. Res., 37, 1015-1030, 2001. 9461, 9462, 9466

Brussaard C. P. D., Noordeloos, A. A. M., Witte, H., Collenteur, M., Schulz, K. G., Ludwig, A., Czerny, J., and Riebesell, U.: Ocean acidification impact on Arctic microbial dynamics, Biogeosciences Discuss., in preparation, 2012. 9459

Carpenter, S. R., Cole, J. J., Pace, M. L., Van de Bogert, M., Bade, D. L., Bastviken, D., Gille, C. M., Hodgson, J. R., Kitchell, J. F., and Kritzberg, E. S.: Ecosystem subsidies: terrestrial support of aquatic food webs from ${ }^{13} \mathrm{C}$ addition to contrasting lakes, Ecology, 86, 2737-2750, 2005. 9469

\section{BGD}

9, 9453-9486, 2012

Isotopes in inverse modeling

T. Van Engeland et al.

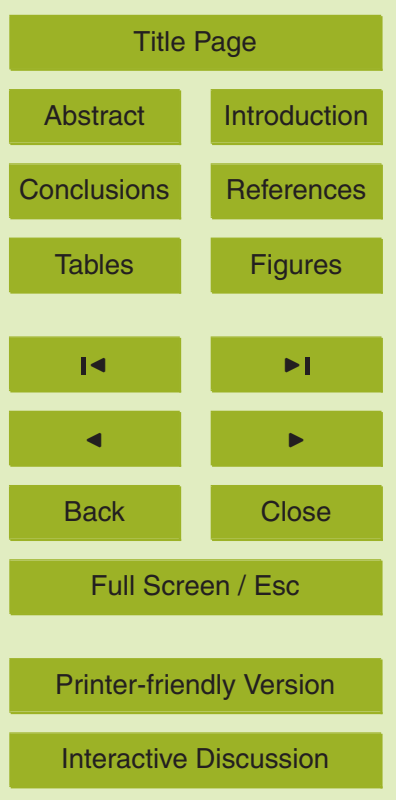

Interactive Discussion 
Cole, J. J., Carpenter, S. R., Kitchell, J. F., and Pace, M. L.: Pathways of organic carbon utilization in small lakes: results from a whole-lake C-13 addition and coupled model, Limnol. Oceanogr., 47, 1664-1675, 2002. 9456

Czerny, J., Bellerby, R. G. J., Boxhammer, T., Engel, A., Krug, S. A., Ludwig, A., Nachtigall, K., $5 \quad$ Niehoff, B., Schulz, K. G., and Riebesell, U.: Element budgets in an arctic mesocosm $\mathrm{CO}_{2}$ perturbation study, Biogeosciences Discuss., in preparation, 2012. 9457, 9458

De Kluijver, A., Soetaert, K., Schulz, K. G., Riebesell, U., Bellerby, R. G. J., and Middelburg, J. J.: Phytoplankton-bacteria coupling under elevated $\mathrm{CO}_{2}$ levels: a stable isotope labelling study, Biogeosciences, 7, 3783-3797, doi:10.5194/bg-7-3783-2010, 2010. 9456

De Kluijver, A., Soetaert, K., Czerny, J., Schulz, K. G., Boxhammer, T., Riebesell, U., and Middelburg, J. J.: A ${ }^{13} \mathrm{C}$ labelling study of carbon fluxes in Arctic plankton communities under elevated $\mathrm{CO}_{2}$ levels, Biogeosciences Discuss., 2012. 9457, 9458, 9459, 9460, 9468, 9469, 9470

Gehlen, M., Gangstø, R., Schneider, B., Bopp, L., Aumont, O., and Ethe, C.: The fate of pelagic $\mathrm{CaCO}_{3}$ production in a high $\mathrm{CO}_{2}$ ocean: a model study, Biogeosciences, 4, 505519, doi:10.5194/bg-4-505-2007, 2007. 9455

Gelman, A., Carlin, J. B., Stern, H. S., and Rubin, D. B.: Bayesian Data Analysis, Chapman \& Hall/CRC, Boca Raton, FL, 2004. 9464

Haario, H., Laine, M., Mira, A., and Saksman, E.: DRAM: efficient adaptive MCMC, Stat. Comput., 16, 339-354, 2006. 9464

Jackson, G. A. and Eldridge, P. M.: Food web analysis of a planktonic system off Southern California, Prog. Oceanogr., 30, 223-251, 1992. 9455, 9470

Joassin, P., Delille, B., Soetaert, K., Harlay, J., Borges, A., Chou, L., Riebesell, U., Suykens, K., and Grégoire, M.: Carbon and nitrogen flows during a bloom of the coccolithophore Emiliania huxleyi: modelling a mesocosm experiment, J. Marine Syst., 85, 71-85, 2011. 9455

Jørgensen, B. B.: Theoretical model of stable sulfur isotope distribution in marine sediments, Geochim. Cosmochim. Acta, 43, 363-374, 1979. 9456

Koopmans, C. and Dam, D. V.: Modelling the impact of lowered atmospheric nitrogen deposition on a nitrogen saturated forest ecosystem, Water Air Soil Poll., 104, 181-203, 1998. 9456

30 Larsson, U. and Hagström, Å.: Fractionated phytoplankton primary production, exudate release and bacterial production in a Baltic eutrophication gradient, Mar. Biol., 67, 57-70, 1982. 9469

Matear, R.: Parameter optimization and analysis of ecosystem models using simulated annealing: a case study at Station P, J. Mar. Res., 53, 571-607, 1995. 9455

\section{BGD}

9, 9453-9486, 2012

Isotopes in inverse modeling

T. Van Engeland et al.

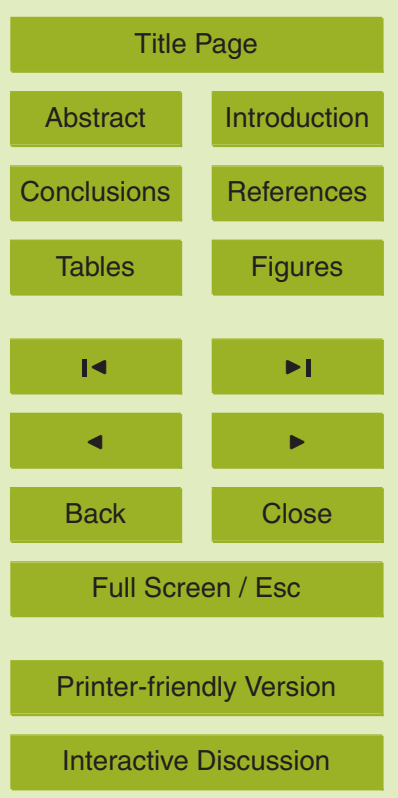


Morán, X. A. G. and Estrada, M.: Phytoplanktonic DOC and POC production in the Bransfield and Gerlache Straits as derived from kinetic experiments of ${ }^{14} \mathrm{C}$ incorporation, Deep-Sea Res. Pt. II, 49, 769-786, 2002. 9469

Moré, J.: The Levenberg-Marquardt algorithm: Implementation and theory, in: Numerical Anal5 ysis, edited by: G. Watson, vol. 630 of Lecture Notes in Mathematics, Springer, Berlin, Heidelberg, 105-116, 1978. 9464

Niehoff B., Knüppel, N., Daase, M., Czerny J., and Boxhammer T.: Ocean acidification effects on zooplankton abundance, Biogeosciences Discuss., in preparation, 2012. 9459, 9460

Post, D. M.: Using stable isotopes to estimate trophic position: models, methods, and assumptions, Ecology, 83, 703-718, 2002. 9456, 9469

R Development Core Team: R: A Language and Environment for Statistical Computing, R Foundation for Statistical Computing, Vienna, Austria, available at: http://www.R-project.org, ISBN 3-900051-07-0, 2011. 9461

Raick, C., Soetaert, K., and Grégoire, M.: Model complexity and performance: how far can we simplify?, Prog. Oceanogr., 70, 27-57, 2006. 9455

Ridgwell, A., Hargreaves, J. C., Edwards, N. R., Annan, J. D., Lenton, T. M., Marsh, R., Yool, A., and Watson, A.: Marine geochemical data assimilation in an efficient Earth System Model of global biogeochemical cycling, Biogeosciences, 4, 87-104, doi:10.5194/bg-4-87-2007, 2007. 9455

20 Riebesell, U., Schulz, K. G., Bellerby, R. G. J., Botros, M., Fritsche, P., Meyerhöfer, M., Neill, C., Nondal, G., Oschlies, A., Wohlers, J., and Zöllner, E.: Enhanced biological carbon consumption in a high $\mathrm{CO}_{2}$ ocean, Nature, 450, 545-548, 2007. 9468

Rose, K., Megrey, B., Werner, F., and Ware, D.: Calibration of the NEMURO nutrientphytoplankton-zooplankton food web model to a coastal ecosystem: evaluation of an automated calibration approach, Ecol. Model., 202, 38-51, 2007. 9466

Schulz, K. G., Bellerby, R. G. J., Brussaard, C., Büdenbender, J., Czerny, J., Fischer, M., KochKlavsen, S., Krug, S., Lischka, S., Ludwig, A., Meyerhöfer, M., Nondal, G., Silyakova, A., Stuhr, A., and Riebesell, U.: Temporal biomass dynamics of an Arctic plankton bloom in response to increasing levels of atmospheric carbon dioxide, Biogeosciences Discuss., in preparation, 2012. 9457

Soetaert, K. and Petzoldt, T.: Inverse modelling, sensitivity and Monte Carlo analysis in R using package FME, J. Stat. Softw., 33, 1-28, 2010. 9461, 9464

\section{BGD}

9, 9453-9486, 2012

Isotopes in inverse modeling

T. Van Engeland et al.

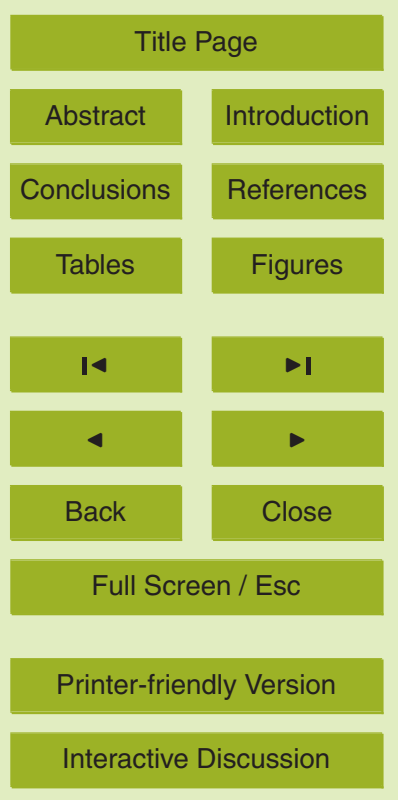


Soetaert, K., Petzoldt, T., and Setzer, R. W.: Solving differential equations in R: package deSolve, J. Stat. Softw., 33, 1-25, 2010. 9461

Stukel, M. R., Landry, M. R., Ohman, M. D., Goericke, R., Samo, T., and Benitez-Nelson, C. R.: Do inverse ecosystem models accurately reconstruct plankton trophic flows? Comparing 5 two solution methods using field data from the California Current, J. Marine Syst., 91, 20-33, 2012. 9455

Vallino, J. J.: Improving marine ecosystem models: use of data assimilation and mesocosm experiments, J. Marine Syst., 58, 117-164, 2000. 9454

Van den Meersche, K., Middelburg, J. J., Soetaert, K., van Rijswijk, P., Boschker, H. T. S., and Heip, C. H. R.: Carbon-nitrogen coupling and algal-bacterial interactions during an experimental bloom: modeling a C-13 tracer experiment, Limnol. Oceanogr., 49, 862-878, 2004. 9456

Van den Meersche, K., Soetaert, K., and Middelburg, J. J.: Plankton dynamics in an estuarine plume: a mesocosm ${ }^{13} \mathrm{C}$ and ${ }^{15} \mathrm{~N}$ tracer study, Mar. Ecol.-Prog. Ser., 29-43, 2011. 9469

Van Oevelen, D., Soetaert, K., Middelburg, J. J., Herman, P. M. J., Moodley, L., Hamels, I., Moens, T., and Heip, C. H. R.: Carbon flows through a benthic food web: integrating biomass, isotope and tracer data, J. Mar. Res., 64, 453-482, 2006. 9456

Van Oevelen, D., Van den Meersche, K., Meysman, F. J. R., Soetaert, K., Middelburg, J. J., and Vézina, A. F.: Quantifying food web flows using linear inverse models, Ecosystems, 13, $20 \quad 32-45,2010.9455$

Ward, B. A., Friedrichs, M. A. M., Anderson, T. R., and Oschlies, A.: Parameter optimisation techniques and the problem of underdetermination in marine biogeochemical models, J. Marine Syst., 81, 34-43, 2010. 9471

Zobitz, J. M., Desai, A. R., Moore, D. J. P., and Chadwick, M. A.: A primer for data assimilation with ecological models using Markov Chain Monte Carlo (MCMC), Oecologia, 167, 599-611, 2011. 9466

\section{BGD}

9, 9453-9486, 2012

Isotopes in inverse modeling

T. Van Engeland et al.

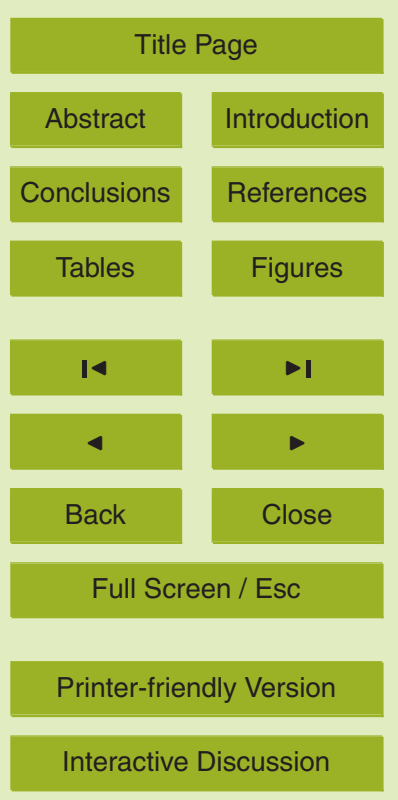


Table 1. State variables, model forcings, and derived output variables for which calibration data were available. The ${ }^{*}$ indicates availability of a data counterpart for calibration. The subscript $i$ refers to the two phytoplankton groups $(i \in\{I, I I\})$.

\begin{tabular}{|c|c|c|c|}
\hline Acronym & Description & Units & \\
\hline \multicolumn{4}{|c|}{ State variables } \\
\hline DIN & Dissolved inorganic nitrogen & $\mathrm{mmol} \mathrm{m}^{-3}$ & * \\
\hline DON & Dissolved organic nitrogen & $\mathrm{mmol} \mathrm{m}^{-3}$ & * \\
\hline${ }^{13} \mathrm{C}_{\text {Phyto }}$ & ${ }^{13} \mathrm{C}$ in phytoplankton group i & $\mathrm{mmol} \mathrm{m}^{-3}$ & \\
\hline${ }^{12} \mathrm{C}_{\text {Phyto }}$ & ${ }^{12} \mathrm{C}$ in phytoplankton group i & $\mathrm{mmol} \mathrm{m}^{-3}$ & \\
\hline${ }^{13} \mathrm{C}_{\text {Zoo }}$ & ${ }^{13} \mathrm{C}$ in zooplankton & $\mathrm{mmol} \mathrm{m}^{-3}$ & \\
\hline${ }^{13} \mathrm{C}_{\text {Det }}^{200}$ & ${ }^{13} \mathrm{C}$ in detritus & $\mathrm{mmol} \mathrm{m}^{-3}$ & \\
\hline${ }^{12} \mathrm{C}_{\text {Det }}$ & ${ }^{12} \mathrm{C}$ in detritus & $\mathrm{mmol} \mathrm{m}^{-3}$ & \\
\hline${ }^{13} \mathrm{C}_{\mathrm{Bac}}$ & ${ }^{13} \mathrm{C}$ in bacteria & $\mathrm{mmol} \mathrm{m}^{-3}$ & \\
\hline${ }^{13} \mathrm{C}_{\text {LDOC }}$ & ${ }^{13} \mathrm{C}$ in labile dissolved organic carbon & $\mathrm{mmol} \mathrm{m}^{-3}$ & \\
\hline${ }^{12} \mathrm{C}_{\text {LDOC }}$ & ${ }^{12} \mathrm{C}$ in labile dissolved organic carbon & $\mathrm{mmol} \mathrm{m}^{-3}$ & \\
\hline${ }^{13} \mathrm{C}_{\text {Sed }}$ & ${ }^{13} \mathrm{C}$ in sedimented detritus & $\mathrm{mmol} \mathrm{m}^{-3}$ & \\
\hline${ }^{12} \mathrm{C}_{\text {Sed }}$ & ${ }^{12} \mathrm{C}$ in sedimented detritus & $\mathrm{mmol} \mathrm{m} \mathrm{m}^{-3}$ & \\
\hline \multicolumn{4}{|c|}{ Forcing functions } \\
\hline${ }^{13} \mathrm{C}_{\mathrm{DIC}}$ & ${ }^{13} \mathrm{C}$ in dissolved inorganic carbon & $\mathrm{mmol} \mathrm{m}^{-3}$ & \\
\hline${ }^{12} \mathrm{C}_{\mathrm{DIC}}$ & ${ }^{12} \mathrm{C}$ in dissolved inorganic carbon & $\mathrm{mmol} \mathrm{m}^{-3}$ & \\
\hline & Irradiance & $\mathrm{W} \mathrm{m}^{-2}$ & \\
\hline & \multicolumn{3}{|l|}{ Derived output variables relevant for calibration } \\
\hline $\mathrm{DOC}_{\text {tot }}$ & Total DOC (labile + refractory background) & $\mathrm{mmol} \mathrm{m}^{-3}$ & * \\
\hline $\mathrm{POC}$ & Particulate organic carbon & $\mathrm{mmol} \mathrm{m}^{-3}$ & * \\
\hline PON & Particulate organic nitrogen & $\mathrm{mmol} \mathrm{m}^{-3}$ & * \\
\hline $\mathrm{C}_{\text {Phyto }}$ & Carbon in phytoplankton group i & $\mathrm{mmol} \mathrm{m}^{-3}$ & * \\
\hline $\mathrm{C}_{\text {Sed }}$ & Carbon in sedimented detritus & $\mathrm{mmol} \mathrm{m}^{-3}$ & * \\
\hline $\mathrm{N}_{\text {Sed }}$ & Nitrogen in sedimented detritus & $\mathrm{mmol} \mathrm{m}^{-3}$ & * \\
\hline$\delta^{13} \mathrm{C}_{\text {Phyto }_{\mathrm{i}}}$ & $\delta^{13} \mathrm{C}$ of phytoplankton group i & \%。 & * \\
\hline$\delta^{13} \mathrm{C}_{\mathrm{Zoo}}$ & $\delta^{13} \mathrm{C}$ in zooplankton & $\%$ & * \\
\hline$\delta^{13} \mathrm{C}_{\text {Bact }}$ & $\delta^{13} \mathrm{C}$ in bacteria & $\%$ & * \\
\hline$\delta^{13} \mathrm{C}_{\text {Sed }}$ & $\delta^{13} \mathrm{C}$ in sedimented detritus & $\%$ & * \\
\hline$\delta^{13} \mathrm{C}_{\mathrm{POC}}$ & $\delta^{13} \mathrm{C}$ in $\mathrm{POC}$ & $\%$ & * \\
\hline
\end{tabular}

\section{BGD}

9, 9453-9486, 2012

\section{Isotopes in inverse modeling}

T. Van Engeland et al.

Title Page

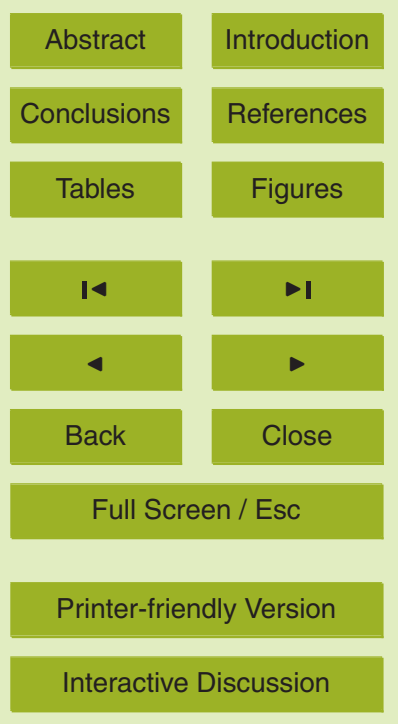


Table 2. Rate equations, mass balance equations for the state variables, and equations for the calculation of derived output variables. The subscript i refers to the phytoplankton groups $(i \in\{I, I I\})$. The superscript $x$ refers to the carbon isotope $(x \in\{12,13\})$.

\begin{tabular}{|c|c|c|c|}
\hline Rate equations & & & \\
\hline$F_{\mathrm{DIC}}^{13}=$ pref $\times \frac{{ }^{13} \mathrm{C}_{\mathrm{DIC}}}{{ }^{13} \mathrm{C}_{\mathrm{DIC}}+{ }^{12} \mathrm{C}_{\mathrm{DIC}}}$ & (4) & Loss $_{\text {Zoo }}^{\text {Det }}=f_{\text {faeces }} \times \sum_{\mathrm{i}} g_{\text {raz }}$ Phyto $_{\mathrm{i}}$ & (13) \\
\hline growth $_{\text {Phyto }_{\mathrm{i}}}=\mu_{\mathrm{i}} \times \frac{\mathrm{DIN}}{\mathrm{DIN}+k s_{\mathrm{N}}} \times \frac{1}{I+k s_{\mathrm{I}}} \times \mathrm{C}_{\mathrm{Phyto}_{\mathrm{i}}}$ & (5) & $\operatorname{Loss}_{\text {Zoo }^{\text {Sed }}}=f_{\text {sink }} \times \sum_{\mathrm{i}}$ graz $_{\text {Phyto }_{\mathrm{i}}}$ & (14) \\
\hline mort $_{\text {Phyto }_{\mathrm{i}}}=\xi_{\mathrm{i}} \times \mathrm{C}_{\text {Phyto }_{\mathrm{i}}}$ & (6) & growth $_{\mathrm{Bac}}=\mu_{\mathrm{Bac}} \times \frac{\mathrm{LDOC}}{\mathrm{LDOC}+k s_{\mathrm{DOC}}} \times C_{\mathrm{Bac}}$ & (15) \\
\hline Loss $_{\text {Phyto }_{i}}^{\text {DOM }}=f_{\text {DOM }} \times$ mort $_{\text {Phyto }_{i}}$ & (7) & $\operatorname{resp}_{\mathrm{Bac}}=$ growth $_{\mathrm{Bac}}$ & (16) \\
\hline Loss $_{\text {Phyto }_{i}}^{\text {Det }}=f_{\text {Det }} \times$ mort $_{\text {Phyto }_{i}}$ & (8) & $\min _{\mathrm{DON}}=\rho \times \mathrm{DON}$ & (17) \\
\hline $\operatorname{resp}_{\text {Phyto }_{\mathrm{i}}}=\left(1-f_{\text {Det }}-f_{\mathrm{DOM}}\right) \times \sum_{\mathrm{i}}$ mort $_{\text {Phyto }_{\mathrm{i}}}$ & (9) & $\min _{\text {Det }}=\rho \times \mathrm{C}_{\text {Det }}$ & (18) \\
\hline exud $_{\text {Phyto }_{\mathrm{i}}}=\gamma_{\mathrm{i}} \times$ growth $_{\text {Phyto }_{\mathrm{i}}}$ & $(10)$ & sinking $=r_{\text {sink }} \times C_{\text {Det }}$ & (19) \\
\hline graz $_{\text {Phyto }_{\mathrm{i}}}=\mu_{\mathrm{g}} \times \frac{\mathrm{C}_{\mathrm{Phyto}_{\mathrm{i}}}}{\mathrm{C}_{\mathrm{Phyto}_{\mathrm{i}}}+k s_{\mathrm{g}}} \times C_{\mathrm{Zoo}}$ & (11) & $r e s p=\sum_{\mathrm{i}} r e s p_{\mathrm{Phyto}_{\mathrm{i}}}+r e s p_{\mathrm{Zoo}}+r e s p_{\mathrm{Bac}}$ & (20) \\
\hline$r e s p_{\text {Zoo }}=\left(1-f_{\text {faeces }}-f_{\text {sink }}\right) \times \sum_{i} g_{\text {raz }}$ Phyto $_{\mathrm{i}}$ & (12) & & \\
\hline
\end{tabular}

\section{BGD}

9, 9453-9486, 2012

Isotopes in inverse modeling

T. Van Engeland et al.

Title Page

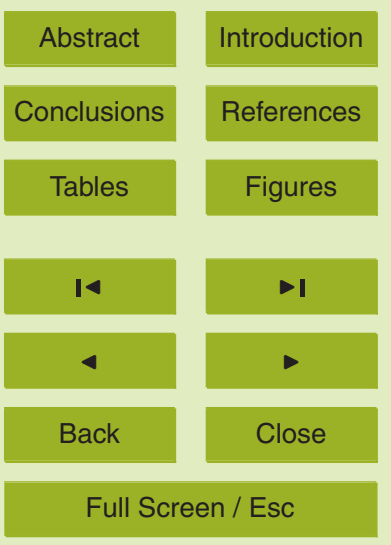

Printer-friendly Version

Interactive Discussion 
Table 2. (Continued.)

BGD

Mass balance equations

$\frac{\mathrm{d} \text { DIN }}{\mathrm{d} t}=\left(-\sum_{\mathrm{i}}\right.$ growth $_{\mathrm{Phyto}_{\mathrm{i}}}+\min _{\mathrm{Det}}+$ resp $) \times N C+\min _{\mathrm{DON}}$

$\frac{\mathrm{d} \mathrm{DON}}{\mathrm{d} t}=\left(\sum_{\mathrm{i}} \mathrm{exu}_{\mathrm{Phyto}_{\mathrm{i}}}-\right.$ growth $\left._{\mathrm{Bac}}\right) \times N C+\sum_{\mathrm{i}} \operatorname{Loss}_{\mathrm{Phyto}_{\mathrm{i}}}^{\mathrm{DOM}} \times N C-\min _{\mathrm{DON}}$

$\frac{\mathrm{d}^{\mathrm{x}} \mathrm{C}_{\mathrm{Phyto}_{\mathrm{i}}}}{\mathrm{d} t}=$ growth $_{\text {Phyto }_{\mathrm{i}}} \times F_{\mathrm{DIC}^{\mathrm{x}} \mathrm{C}}-\left(\right.$ mort $_{\text {Phyto }_{\mathrm{i}}}+$ graz $_{\text {Phyto }_{\mathrm{i}}}+$ ex $\left._{\text {Phyto }_{\mathrm{i}}}\right) \times F_{\text {Phyto }_{\mathrm{i}}}^{\mathrm{x} \mathrm{C}}$

$\frac{\mathrm{d}^{\mathrm{x}} \mathrm{C}_{\text {Det }}}{\mathrm{d} t}=\sum\left[F_{\mathrm{Phyto}_{\mathrm{i}}^{\mathrm{x}}}^{\mathrm{C}} \times \operatorname{Loss}_{\mathrm{Phyto}_{\mathrm{i}}}^{\text {Det }}+F_{\text {Zoo }}^{\mathrm{x} \mathrm{C}} \times \operatorname{Loss}_{\text {Zoo }}^{\text {Det }}\right]-F_{\text {Det }}^{\mathrm{x} C} \times\left(\min _{\text {Det }}+\sin k i n g\right)$

$\frac{\mathrm{d}^{\mathrm{x}} \mathrm{C}_{\mathrm{LDOC}}}{\mathrm{d} t}=\sum_{\mathrm{i}}\left[F_{\text {Phyto }_{\mathrm{i}}^{\mathrm{x}}}^{\mathrm{C}} \times\left(\right.\right.$ exud $_{\mathrm{Phyto}_{\mathrm{i}}}+$ Loss $\left.\left._{\mathrm{Phyto}_{\mathrm{i}}}^{\mathrm{DOM}}\right)\right]-F_{\mathrm{LDOC}^{\mathrm{x}}}^{\mathrm{C}} \times$ growth $_{\mathrm{Bac}}$

$\frac{\mathrm{d}^{\mathrm{x}} \mathrm{C}_{\mathrm{Sed}}}{\mathrm{d} t}=F_{\mathrm{Det}}^{\mathrm{x}} \mathrm{C} \times \operatorname{sinking}+F_{\mathrm{Zoo}}^{\mathrm{x} C} \times \operatorname{Loss}_{\mathrm{Zoo}}^{\mathrm{Sed}}$

$\frac{\mathrm{d}^{13} \mathrm{C}_{\mathrm{Bac}}}{\mathrm{d} t}=$ growth $_{\mathrm{Bac}} \times\left(\mathrm{F}_{\mathrm{LDOC}}^{13} \mathrm{C}-F_{\mathrm{Bac}}^{13} \mathrm{C}\right)$

$\frac{\mathrm{d}^{13} \mathrm{C}_{\mathrm{Zoo}}}{\mathrm{d} t}=\sum_{\mathrm{i}}\left[\left(1-f_{\text {faeces }}\right) \times\right.$ graz $\left._{\text {Phyto }_{\mathrm{i}}} \times\left(\mathrm{F}_{\text {Phyto }_{\mathrm{i}}}^{{ }^{3} \mathrm{C}}-F_{\mathrm{Zoo}^{13} \mathrm{C}}\right)\right]$

Additional output variables

$\mathrm{C}_{\text {Phyto }_{\mathrm{i}}}={ }^{13} \mathrm{C}_{\text {Phyto }_{\mathrm{i}}}+{ }^{12} \mathrm{C}_{\text {Phyto }_{\mathrm{i}}}$

$C_{\text {Det }}={ }^{13} C_{\text {Det }}+{ }^{12} C_{\text {Det }}$

$\mathrm{C}_{\text {Sed }}={ }^{13} \mathrm{C}_{\text {Sed }}+{ }^{12} \mathrm{C}_{\text {Sed }}$

$\mathrm{N}_{\text {Sed }}=\mathrm{C}_{\text {Sed }} \times N C$

LDOC $={ }^{13} \mathrm{C}_{\text {LDOC }}+{ }^{12} \mathrm{C}_{\text {LDOC }}$

$\mathrm{POC}=\sum \mathrm{C}_{\mathrm{Phyto}_{\mathrm{i}}}+C_{\mathrm{Zoo}}+\mathrm{C}_{\mathrm{Det}}+C_{\mathrm{Bac}}$

$\mathrm{PON}=\mathrm{POC} \times N C$

$\mathrm{DOC}_{\text {tot }}=D O C+\mathrm{LDOC}$

9, 9453-9486, 2012

Isotopes in inverse modeling

T. Van Engeland et al.

Title Page

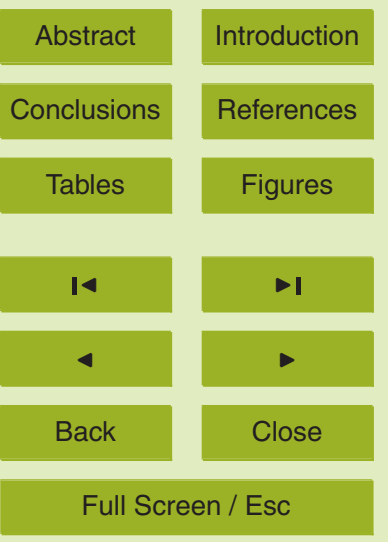

Printer-friendly Version

Interactive Discussion 
Table 3. Parameter values. Parameters in the upper half of the table were initially considered for automatic calibration. Values in bold are eventually selected for estimation by the Markov-Chain Monte-Carlo (MCMC) procedure.

\begin{tabular}{|c|c|c|c|}
\hline Acronym & Description & Value & Units \\
\hline$\mu_{l}$ & Maximal growth rate for Phyto, & 0.91 & $d^{-1}$ \\
\hline$\mu_{\|}$ & Maximal growth rate for $\mathrm{Phyto}_{\|}$ & 0.19 & $d^{-1}$ \\
\hline$\xi_{1}^{\prime \prime}$ & Mortality for Phyto & 0.25 & $d^{-1}$ \\
\hline$\xi_{\| 1}$ & Mortality for $\mathrm{Phyto}_{\|}$ & 0.06 & $d^{-1}$ \\
\hline$\gamma_{l}$ & DOM exudation rate for Phyto, & 0.4 & $d^{-1}$ \\
\hline$\gamma_{\| \prime}$ & DOM exudation rate for $\mathrm{Phyto}_{\|}$ & 0.4 & $d^{-1}$ \\
\hline$\mu_{B a c}$ & Bacteria maximal growth rate & 0.13 & $d^{-1}$ \\
\hline$\rho$ & Mineralisation rate & 0.024 & $d^{-1}$ \\
\hline$\mu_{g}$ & Maximal phytoplankton grazing rate & 0.19 & $d^{-1}$ \\
\hline$\xi_{\text {Zoo }}$ & Zooplankton loss to sediment traps & 0.48 & \\
\hline$r_{\text {sink }}$ & Detritus sinking rate & 0.001 & $d^{-1}$ \\
\hline$k s_{1}$ & Irradiance half-saturation constant & 100 & $\mathrm{Wm}^{-2}$ \\
\hline$k s_{\mathrm{N}}$ & Half-saturation constant for DIN uptake & 0.5 & $\mathrm{mmolm}^{-3}$ \\
\hline$k s_{\mathrm{DOC}}$ & Half-saturation constant for DOC uptake & 0.001 & $\mathrm{mmolm}^{-3}$ \\
\hline$k s_{\mathrm{g}}$ & Half-saturation constant for grazing on phytoplankton & 1 & $\mathrm{mmolm}^{-3}$ \\
\hline$f_{\mathrm{DOM}}$ & Fraction of phytoplankton mortality channelled to DOM & 0.32 & - \\
\hline$f_{\text {Det }}$ & Fraction of phytoplankton mortality channelled to detritus & 0.5 & - \\
\hline$f_{\text {faeces }}$ & Fraction of grazing channelled to detritus & 0 & - \\
\hline NC & Fixed $\mathrm{N}: \mathrm{C}$ ratio used for all compartments & $16 / 106$ & $\mathrm{molmol}^{-1}$ \\
\hline pref & Constant for isotope fractionation in carbon fixation & 0.956 & - \\
\hline$C_{\mathrm{Bac}}$ & Bacterial biomass, assumed constant & 4.4 & $\mathrm{mmolm}^{-3}$ \\
\hline$C_{\text {Zoo }}$ & Zooplankton biomass, assumed constant & 5 & $\mathrm{mmolm}^{-3}$ \\
\hline$D O C$ & Refractory DOC, assumed constant & 78 & $\mathrm{mmolm}^{-3}$ \\
\hline
\end{tabular}

BGD

9, 9453-9486, 2012

Isotopes in inverse modeling

T. Van Engeland et al.

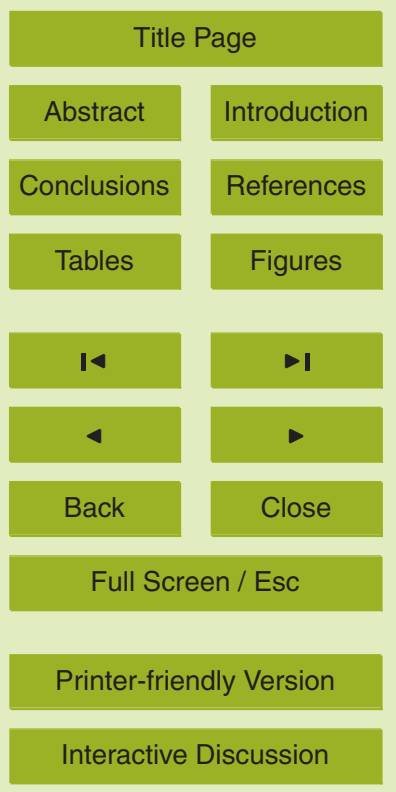




\section{BGD}

9, 9453-9486, 2012

Isotopes in inverse modeling

Table 4. Parameter estimates from the Levenberg-Marquardt fitting algorithm (LMA; based on the full dataset) and the Markov-Chain Monte-Carlo simulation (MCMC). The LMA and $\mathrm{MCMC}_{\text {full }}$ results are based on the full dataset (with isotope data), $\mathrm{MCMC}_{\text {reduced }}$ on the reduced dataset (without isotope data). LMA returns a significance value $(p)$, both methods (LMA and $\mathrm{MCMC}$ ) return standard deviations (sd) on the estimate.

\begin{tabular}{lrrrrrrr}
\hline & \multicolumn{3}{c}{ LMA } & \multicolumn{2}{c}{ MCMC $_{\text {full }}$} & \multicolumn{2}{c}{ MCMC $_{\text {reduced }}$} \\
& Estimate & sd & $p$ & Estimate & sd & Estimate & sd \\
\hline$\mu_{1}$ & 0.95 & 0.038 & $<0.001$ & 0.91 & 0.037 & 0.85 & 0.067 \\
$\mu_{\| 1}$ & 0.18 & 0.013 & $<0.001$ & 0.19 & 0.0089 & 0.21 & 0.044 \\
$\xi_{\mathrm{I}}$ & 0.25 & 0.027 & $<0.001$ & 0.25 & 0.027 & 0.27 & 0.042 \\
$\xi_{\|}$ & 0.033 & 0.019 & 0.085 & 0.061 & 0.019 & 0.077 & 0.028 \\
$\mu_{\mathrm{g}}$ & 0.018 & 0.0012 & $<0.001$ & 0.019 & 0.0017 & 0.0074 & 0.0039 \\
$r_{\text {sink }}$ & 0.0029 & 0.00076 & $<0.001$ & 0.0014 & 0.0011 & 0.027 & 0.008 \\
$\mu_{\text {Bac }}$ & 0.14 & 0.0087 & $<0.001$ & 0.13 & 0.0068 & 0.11 & 0.03 \\
\hline
\end{tabular}

\section{T. Van Engeland et al.}

Title Page

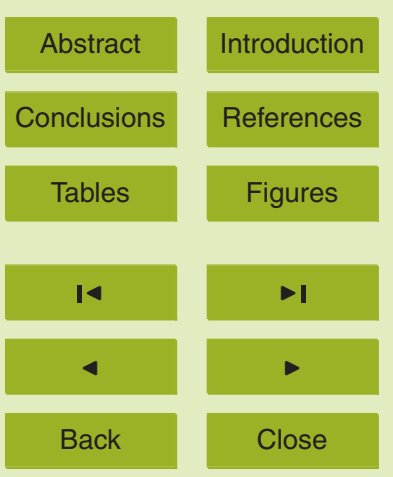

Full Screen / Esc

Printer-friendly Version

Interactive Discussion 


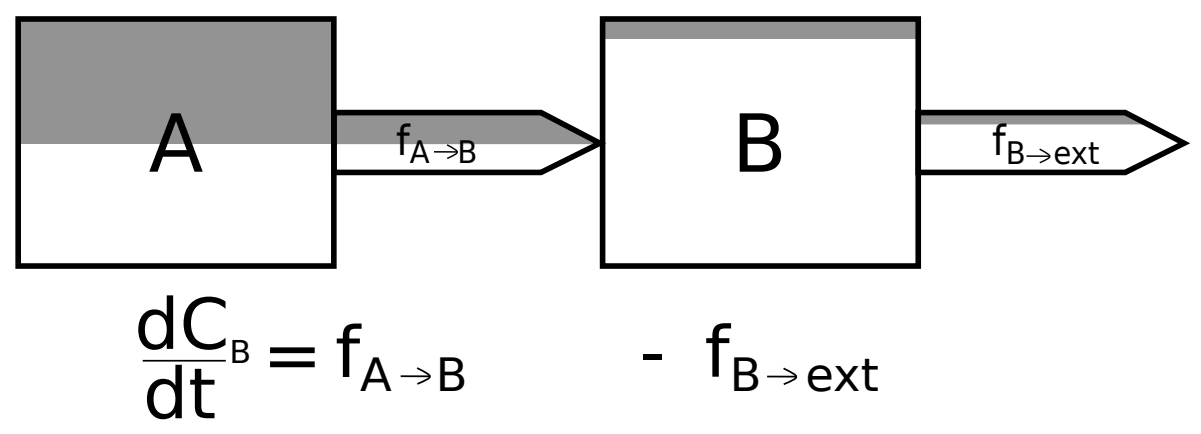

\section{BGD}

9, 9453-9486, 2012

\section{Isotopes in inverse modeling}

T. Van Engeland et al.

$$
\frac{d^{13} C_{B}}{d t}=f_{A \rightarrow B} \times F_{A}^{13} C-f_{B \rightarrow \text { ext }} \times F_{B}^{13}
$$

$$
\frac{d^{12} C_{B}}{d t}=f_{A \rightarrow B} \times F_{A}^{12} C-f_{B \rightarrow \text { ext }} \times F_{B}^{12 C}
$$

Fig. 1. Scheme of relationship between isotope and elemental fluxes $\left(f_{A \rightarrow B}, f_{B \rightarrow e x t}\right)$ and stocks $\left(\mathrm{C}_{\mathrm{A}}, \mathrm{C}_{\mathrm{B}}\right)$, explained with carbon $(\mathrm{C})$ as example. Isotope mass-balance equations are similar to their elemental counterpart, except for the subdivision according to isotope fractions (e.g. $F_{\mathrm{A}}^{13} \mathrm{C}$, $F_{\mathrm{A}}^{12} \mathrm{C}$.

Title Page

Abstract

Introduction

Conclusions

References

Tables

Figures

14

$\rightarrow 1$

4

Back

Close

Full Screen / Esc

Printer-friendly Version

Interactive Discussion 


\section{BGD}

9, 9453-9486, 2012
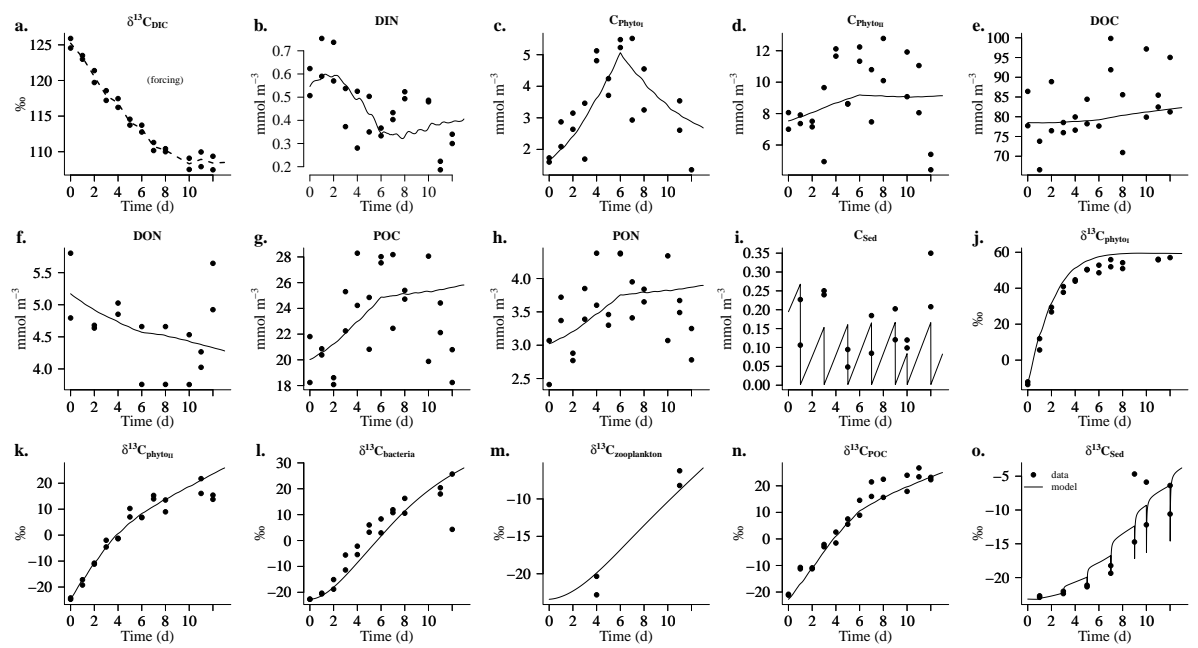

Fig. 2. Experimental dataset used for calibration and model output from a parameterisation based on a Levenberg-Marquardt fit (LMA). $\delta^{13} C_{\mathrm{DIC}}$ is forced upon the model. The sedimented detritus carbon and nitrogen are reset to zero when sediment traps were emptied (hence the zigzag pattern). See Table 1 for a description of the acronyms.

\section{Isotopes in inverse modeling}

T. Van Engeland et al.

Title Page

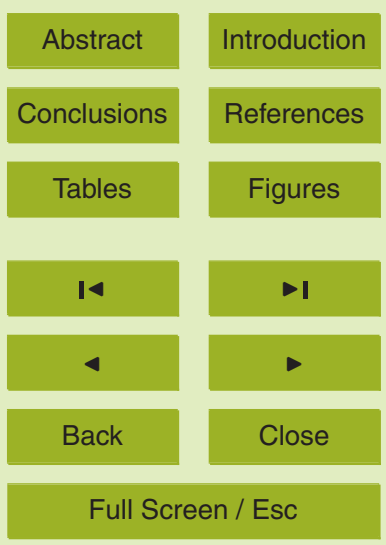

Printer-friendly Version

Interactive Discussion 


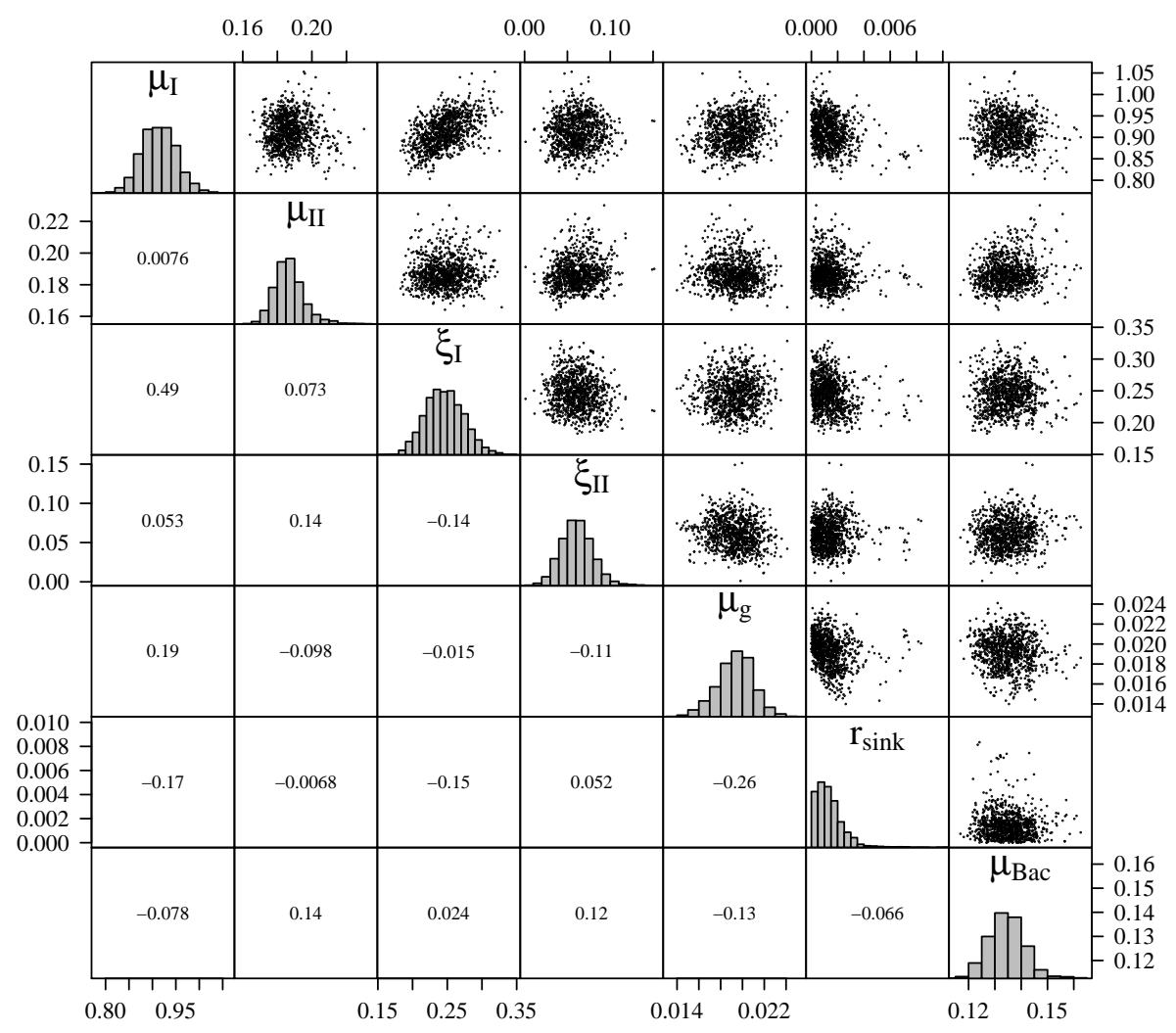

Fig. 3. Parameter covariance matrix from the MCMC calibration with isotopic and concentration data (full dataset). Upper triangle: Pairwise scatterplots of the parameter randomisations. Lower triangle: the corresponding Pearson's correlation coefficients. Diagonal: marginal parameter distributions. The parameter covariance matrix can be considered a joint distribution of the fitted parameters.

\section{BGD}

9, 9453-9486, 2012

Isotopes in inverse modeling

T. Van Engeland et al.

Title Page

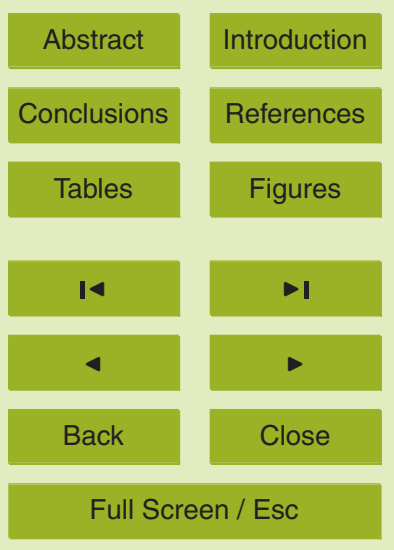

Printer-friendly Version

Interactive Discussion 


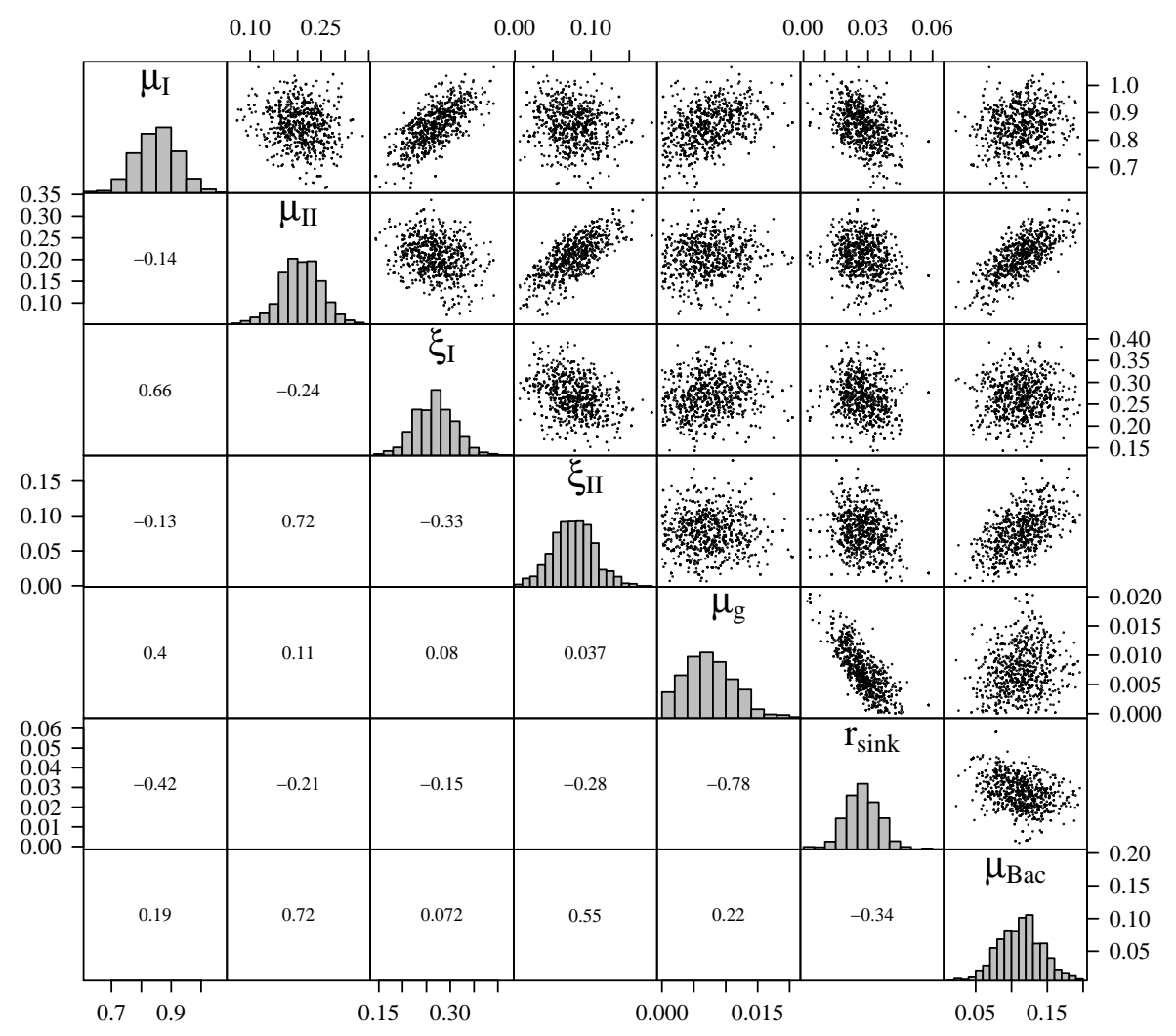

Fig. 4. Parameter covariance matrix from the MCMC calibration without isotopic data (reduced dataset). Upper triangle: Pairwise scatterplots of the parameter randomisations. Lower triangle: the corresponding Pearson's correlation coefficients. Diagonal: marginal parameter distributions. The parameter covariance matrix can be considered a joint distribution of the fitted parameters.

\section{BGD}

9, 9453-9486, 2012

\section{Isotopes in inverse modeling}

T. Van Engeland et al.

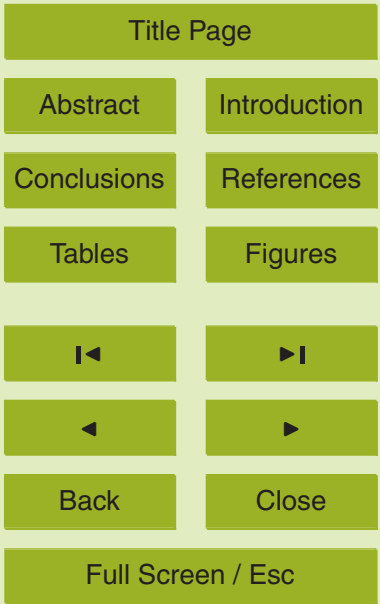

Printer-friendly Version

Interactive Discussion 


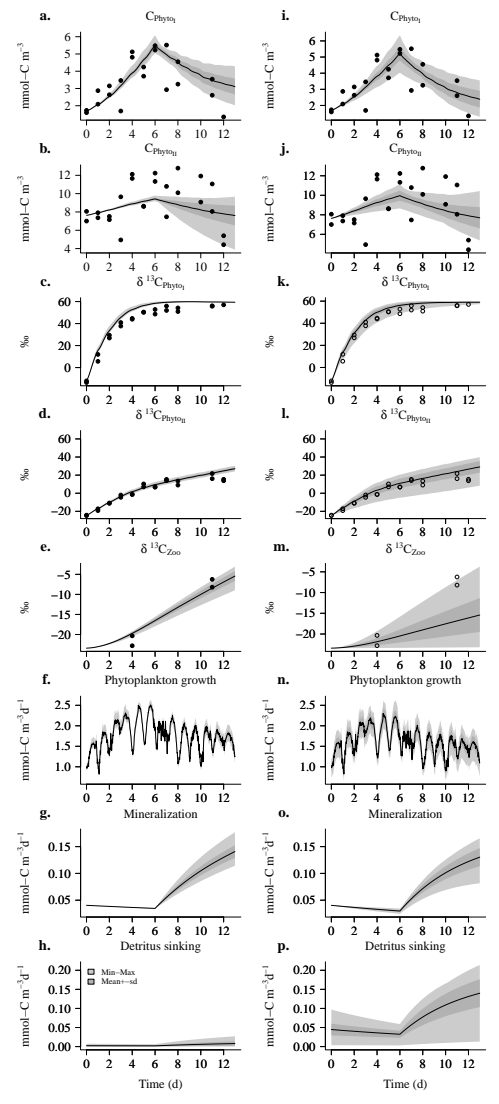

Fig. 5. Comparison of the model output for selected variables and processes, based on the calibration results with the full dataset (left; with isotope tracer data) and the reduced dataset (right; without isotope tracer data). The grey zonation around the mean model output is based on a random parameter sample $(n=100)$ from the respective MCMC calibrations. Observations are indicated in black dots if used for calibration, and in open circles if not. The meaning of the acronyms is given in Table 1 .
BGD

9, 9453-9486, 2012

\section{Isotopes in inverse} modeling

T. Van Engeland et al.

Title Page

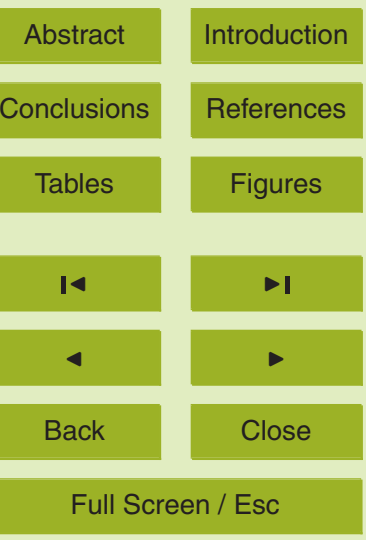

Printer-friendly Version

Interactive Discussion 


\section{BGD}

9, 9453-9486, 2012

a.

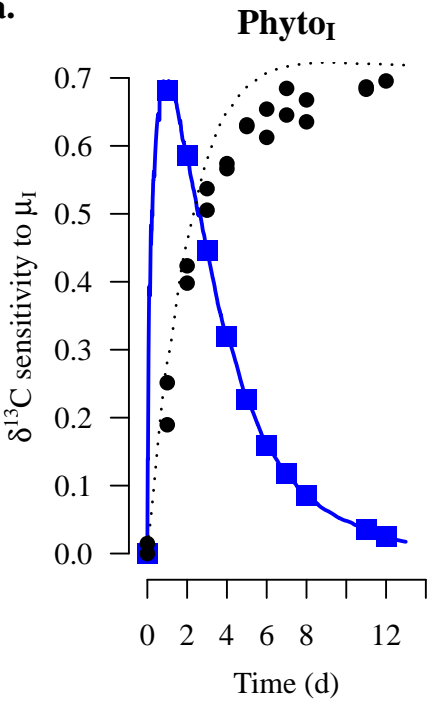

b.

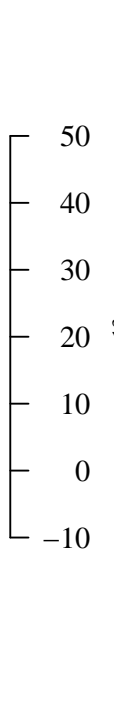

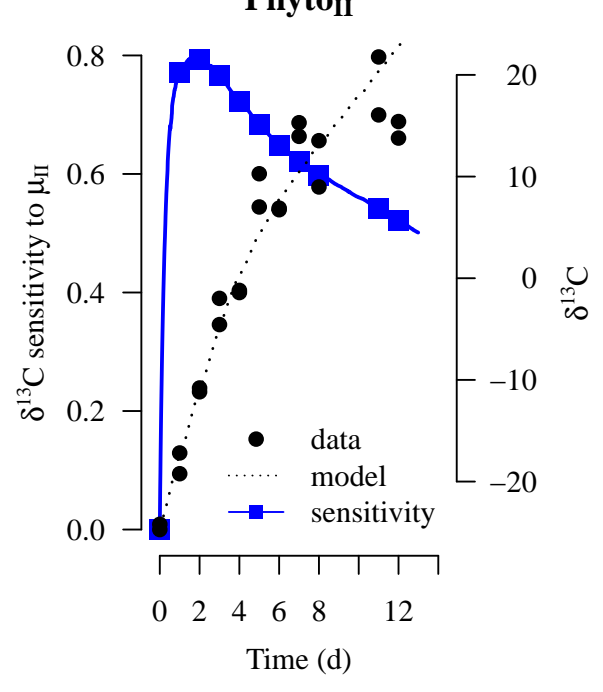

Fig. 6. Relationship between model sensitivity and isotope variability. High sensitivities of $\delta^{13} \mathrm{C}$ to the maximal growth rates for respective phytoplankton groups (left axes) coincide with strong changes in the measured variables and their modelled counterparts (right axes). Note the correspondence between the difference in duration of high sensitivity and the timing of saturation in the $\delta^{13} \mathrm{C}$ signatures.

\section{Isotopes in inverse modeling}

\section{T. Van Engeland et al.}

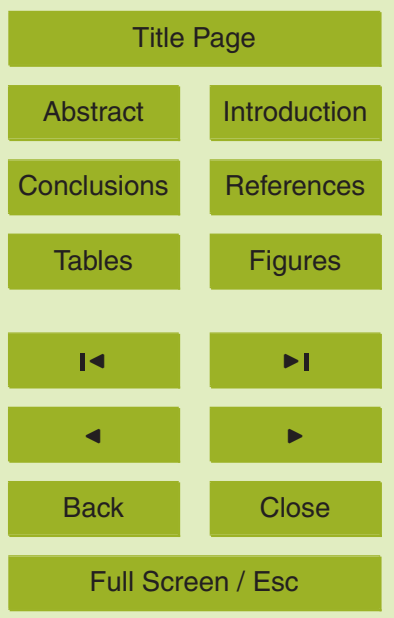

Printer-friendly Version

Interactive Discussion 